\title{
Paying Attention or Paying Too Much in Medicare Part $D$
}

\author{
By Jonathan D. Ketcham, Claudio Lucarelli, \\ ANd Christopher A. Powers*
}

We study whether people became less likely to switch Medicare pre-
scription drug plans (PDPs) due to more options and more time in
Part D. Panel data for a random 20 percent sample of enrollees from
$2006-2010$ show that 50 percent were not in their original PDPs by
2010. Individuals switched PDPs in response to higher costs of their
status quo plans, saving them money. Contrary to choice overload,
larger choice sets increased switching unless the additional plans
were relatively expensive. Neither switching overall nor responsive-
ness to costs declined over time, and above-minimum spending in
2010 remained below the 2006 and 2007 levels. (JEL H51, I13, I18)

Across a range of contexts, researchers are reevaluating the long-held view that consumers benefit from being offered more options. A leading challenge to this view is the hypothesis that facing more options impairs decision making through a set of phenomena known as "choice overload" (Diehl and Poynor 2010; Iyengar and Lepper 2000), "status quo bias" (Samuelson and Zeckhauser 1988), "inertia" (Dube, Hitsch, and Rossi 2010) and "the paradox of choice" in which "more is less" (Schwartz 2004). Each of these terms carries somewhat different connotations and is ascribed to various underlying economic and psychological causes. Their common predictions, however, are that facing more options makes consumers less satisfied with their available options and with their chosen options and more likely to stay with their status quo, even if the status quo is making no purchase at all. Yet a recent experiment on the elderly population specifically (Besedeš et al. 2012) and a meta-analysis by Scheibehenne, Greifeneder, and Todd (2010) yield conclusions antipodal to these other frequently cited studies, concluding instead that consumers benefit from additional options.

\footnotetext{
* Ketcham: Department of Marketing, W.P. Carey School of Business, Arizona State University, Box 874106, Tempe, AZ 85287-4106 (e-mail: Ketcham@asu.edu); Lucarelli: School of Business and Economics, Universidad de los Andes, Mons. Alvaro del Portillo 12455, Santiago, Chile, and Leonard Davis Institute of Health Economics (e-mail: Claudio.Lucarelli@uandes.cl); Powers: Office of Information Products and Data Analytics, Centers for Medicare and Medicaid Services, 7500 Security Boulevard, Mailstop B2-29-04, Baltimore, MD 21244 (e-mail: Christopher.Powers@cms.hhs.gov). Christopher Powers is an employee of the Centers for Medicare and Medicaid Services (CMS). CMS had the right to review the article prior to publication to ensure compliance with standard CMS terminology. Data costs, information technology costs, and Christopher Powers' time were funded internally within the CMS. The views and opinions expressed in this article are those of the authors and do not necessarily reflect the views of CMS. The authors thank Jonah Gelbach, Nicolai Kuminoff, and Christopher Roebuck for their helpful comments, as well as seminar participants at Baylor University.

${ }^{\dagger}$ Go to http://dx.doi.org/10.1257/aer.20120651 to visit the article page for additional materials and author disclosure statement(s).
} 
Similarly divergent evidence exists regarding the effects of experience on the dynamics of consumer decision making. For example, List (2003) and Miravete (2003) provide evidence that learning through experience creates financial benefits to consumers and ameliorates certain types of consumer biases. Studies in a range of other contexts, however, show that as individuals gain experience with a good or service over time, they become less likely to switch to an alternative (Osborne 2011; Heilman, Bowman, and Wright 2000; Prince 2011; Israel 2005a).

Medicare Part D represents a prominent setting where research can provide new insights to these tensions regarding inertia, choice overload, and experience. In contrast with Medicare's traditional design, since its beginning in 2006 Part D has relied on enrollees to choose their prescription drug coverage from private insurers competing within a government-created, taxpayer-subsidized market. Part D's relevance to choice overload stems from the high potential for the presence of such effects given the large number of complex products and the health and demographics of the consumers. Likewise, an attractive feature of Part D for evaluating the effects of experience is that it offers the rare ability for researchers to observe each consumer's entire experience across all firms in the market. Despite researchers' broad interests in the effects of choice overload and experience on consumer decision making and the policy relevance of the Part D context, research has not yet examined how such factors influence consumers' dynamic decisions to switch between Medicare prescription drug plans (PDPs).

This article has two primary objectives. First, we seek to learn how within-person changes in the number of options affects the likelihood of switching and how these effects differ when the additional options are relatively low cost versus relatively expensive to the individual. Second, we evaluate the within-person changes in the likelihood of switching over time. To achieve these objectives we analyze a random 20 percent sample of the entire population enrolled in a PDP, with a few additional criteria for inclusion in our study sample described below. For this sample we rely on rich data and previously untapped institutional knowledge within CMS to develop an accurate method of calculating what each person would have spent in each available plan under a few alternative modeling approaches. We also use these resources to establish accurate measures of switching, experience, and the number of plans available in the region overall and the number available by each level of cost to each individual.

With these data we estimate empirical models of switching between PDPs that account for individual-specific unobserved heterogeneity, within-person changes in health over time, and other factors. To evaluate the role of choice overload on inertia, we rely on within-person changes over time in the total number of plans in their choice set. We also consider how switching decisions vary as the choice set expands due to changes in the number of low cost versus high cost plans and otherwise holding constant the overall choice set size. In our models, we evaluate the main effect of the number of plans on switching. We also study how the number of available plans affects how responsive people are to upcoming changes in their status quo plans' costs relative to the available alternatives.

The results provide no evidence that larger choice sets promote inertia. To the contrary, expanding the choice set by adding more plans increases people's likelihood of switching plans, unless the additional plans are high cost relative to the available 
alternatives. For example, we find that each additional plan available within $\$ 300$ of the individual's minimum cost plan's annual costs increases the likelihood of switching by 0.6 percentage points. The results also provide no evidence that larger choice sets inhibit individuals responsiveness to the costs of their status quo plans. This, too, is inconsistent with the choice overload hypothesis.

We extend these models to evaluate whether people became less responsive to their status quo plans' costs over time. In these models, the net within-person change over time is identified as the net effect of the average conditional year-specific effects for 2007-2010 and the average conditional effect of each additional month of experience. We define experience as the individual-specific number of months spent in the PDP market without a low-income subsidy. To minimize the influence of any other individual-specific factors that may covary with time and experience, these models include additional interaction terms. Specifically, the net effect of time is conditional on any effects that the individual's age, total prescription drug spending, and diagnosis of Alzheimer's disease or other dementia might have on their responsiveness to their status quo plan's relative costs.

The results for the net within-person changes over time show that people were more responsive to high levels of status quo plans' costs in 2008-2010 than they were in 2007. At the same time, they were also less responsive to low levels of their status quo plans' costs in 2008-2009 than 2007. All of these differences from 2007 mostly disappeared in 2010, with the notable exception being that people were still more likely in 2010 than 2007 to switch in response to large increases in their status quo plans' costs in 2010. Underlying these net changes over time are two counteracting effects: whereas the results show overall increases in people's responsiveness to their status quo plans' costs for 2008-2010 relative to 2007, accruing greater individual-specific experience in the PDP market reduced this responsiveness.

Descriptive results complement this evidence from the empirical models. Among those enrolled for two consecutive full years without a low income subsidy, rates of switching between PDPs remained flat for 2008 through 2010, around one percentage point below the 11.7 percent level observed for 2007 . Overall, only 50 percent of those who initially enrolled from January 2006 through December 2009 remained in their original PDP by January 2010. Among those who stayed in the PDP market through 2010, 28 percent had previously switched between PDPs, generating a cumulative savings from switching among that population exceeding $\$ 1$ billion.

In the next section we summarize the related literature on choice overload and experience and its expected implications for consumers' decisions to switch PDPs. Section II provides a description of the CMS data, the methods used to measure the key variables and the trends in those variables from 2006-2010. Results regarding individuals' switching decisions and choice overload are presented in Section III. The role of time in switching decisions is evaluated in Section IV. Section V provides the results from five alternative modeling approaches and Section VI concludes.

\section{Relevance of Existing Research to Medicare Part D}

Prior research has reported evidence for choice overload, whether from increasing the number of options from two to four in a laboratory experiment (Samuelson and Zeckhauser 1988), or by several hundred as for mutual funds (Kempf and Ruenzi 
2006). ${ }^{1}$ Related, Madrian and Shea (2001) found that in the context of 401(k) plans offered by an actual employer, automatic enrollment greatly amplified participant inertia. Specifically, they concluded that status quo bias resulted in the default option being chosen far more frequently simply as a result of being the default. That article did not evaluate how such effects varied with the number or types of options provided. Building on these results and on the work of Klemperer (1995), Speigler (2011) developed a theoretical model to demonstrate that increasing the number of options increases consumers' status quo bias, resulting in greater price variation and suppliers' profits.

Applications of this research to Medicare Part D have been widespread, with particular emphasis on the results of the experiments in Iyengar and Lepper (2000). 2 In Part D, the default option for nonparticipants is to continue not to participate. Likewise, the default for current enrollees during open enrollment is to remain in their status quo plans for the upcoming year. Additionally, the average number of available PDPs faced by individuals in 2006-2010 was 51, based on data described below. In contrast with the conclusions from Iyengar and Lepper (2000), however, satisfaction and participation in Part D both remain high, with 85 percent of participants reporting satisfaction and 90 percent of the Medicare population enrolled in some form of creditable prescription drug coverage (Centers for Medicare and Medicaid Services 2008). ? $^{3}$

The primary existing research supporting restrictions on consumer choice in Part D specifically is Abaluck and Gruber (2011, p. 1109) who conclude that, "consumers would be better off if there were less scope for choosing the wrong plan." Their proposed method of achieving this outcome is by constraining the number of insurance plans available to each person (Abaluck and Gruber 2009). ${ }^{4}$ Yet that research did not examine the effects of the number of available plans directly. Further, it evaluated only the first year of Part D when consumers had no experience in the newly created market and when the complementary information market was still being developed.

In the context of Part D, the important common prediction of the choice overload hypothesis is that expanding the number of options available to an individual, regardless of the added plans' characteristics, will suppress the likelihood that she switches out of her status quo plan. Yet parallel research points out that not all available options will be considered by consumers. Specifically, plans that are dominated on costs may be viewed as irrelevant because their costs fall beyond the consumer's budget constraint (as Kuminoff, Smith, and Timmins 2013 and Banzhaf and Smith 2007 point out for housing markets), or because consumers eliminate them from their consideration to minimize search costs or cognitive processing costs (Stigler 1961; Hauser and Wernerfelt 1990; Mehta, Rajiv, and Srinivasan 2003). In the

\footnotetext{
${ }^{1}$ Tversky and Shafir (1992) and Iyengar and Lepper (2000) represent two other salient experimental examples.

${ }^{2}$ For example, the Rhode Island Health Care Reform Commission in charge of designing the state's health insurance exchange stated that, "studies indicate that people are more likely to make a choice — and be satisfied with their choice-when they face a more limited set of choices," citing Iyengar and Lepper (2000) and Iyengar, Huberman, and Jiang (2004) (Rhode Island Healthcare Reform Commission 2011).

${ }^{3}$ Additional evidence for high participation levels in 2006 is provided in Heiss, McFadden, and Winter (2006) and for 2009 in Neuman and Cubanski (2009). Additional evidence regarding consumers' satisfaction with Part D is available from AARP (2007) and Medicare Today (2012).

${ }^{4}$ For a sampling of health policy articles supporting restricted choice in Part D and in the state health insurance exchanges see Day and Nadash (2012); Mikels, Reed, and Simon (2009); Cummings, Rice, and Hanoch (2009); Tanius et al. (2009); Hoadley (2008); and Huskamp et al. (2000).
} 
Part D context, budget constraints may rule out high cost options, as may "consideration sets" that consumers use to avoid the costs of ascertaining information on other, more difficult to observe attributes such as variance reduction and plan quality. Thus, in contrast to the choice overload hypotheses, indiscriminately expanding the number of options may have no effect on switching decisions. If either budget constraints or consideration sets influence consumers' willingness or ability to evaluate plans but choice overload does not, then adding high cost options should have no effect on switching while adding attractive options may promote switching.

Extending beyond this hypothesized main effect of choice overload, we also consider whether increasing the number of options causes consumers to become less responsive to the relative costs of their status quo plans..$^{5}$ As with the hypothesized main effect, the choice overload hypothesis proposes that the effects of expanded choice sets on consumers' responsiveness to their costs would exist regardless of the relative costs of the additional plans. Due to such concerns, in 2008 and 2009 CMS became more active in denying insurers' applications to sell plans that were viewed as too similar to other plans already sold by the same firm. ${ }^{6}$

In contrast with the subset of studies that have been commonly applied to Part D, the analysis by Scheibehenne, Greifeneder, and Todd (2010) demonstrates that the studies of Iyengar and Lepper (2000) represent outliers, with 50 experiments providing no evidence overall that more options affect satisfaction and purchasing decisions. 7 Instead, they conclude that the existing research demonstrates that "more choice is better if decision makers had well-defined preferences prior to choice" (Scheibehenne, Greifeneder, and Todd 2010, p. 421). Given this condition, it is notable that Iyengar and Lepper (2000, p. 996) state that they intentionally chose participants who would "not already have strong specific preferences" for products or product attributes. Additionally, evidence of choice overload has not been found consistently even in contexts in which people lack substantial prior knowledge about the products. 8

Further contrasting with the predictions of choice overload in Part D is a recent set of experiments on retirement home residents' choices. Specifically, Besedeš et al. (2012, p. 525) evaluated the effects of expanding the choice set from 4 to 8 to 12 options for a product that "can be thought of as health insurance or drug coverage plans." The results showed that expanding the choice set improved people's choices, and these improvements were larger when the set expanded from 8 to 12 options than from 4 to 8 options. Importantly for our context, the study demonstrated that

\footnotetext{
${ }^{5}$ As an example from the health policy literature, Tanius et al. (2009) used a laboratory experiment to conclude that, "individuals have a more difficult time choosing the best option when faced with large number of prescription drug plans than when faced with few." Bundorf and Szrek (2010) implemented an experimental evaluation of choice set size in Part D. They concluded that consumers' benefits and costs increased with choice set size, but they did not evaluate the effects of choice set size on switching plans.

${ }^{6}$ As evidence of the stated motivation for this change, the 2008 Call Letter stated, "CMS will negotiate with [PDP] sponsors to ensure that each bid they submit represents a meaningful variation based on plan characteristics that will provide beneficiaries with substantially different options.... We expect that organizations will take steps to ensure that the array of PDP benefit packages submitted can be reasonably understood and compared by beneficiaries in terms of key plan characteristics" (our emphasis added) (Centers for Medicare and Medicaid Services 2007).

${ }^{7}$ In preceding work, Scheibehenne (2008) was unable to replicate the results from the original Iyengar and Lepper (2000) jam study in Germany.

${ }^{8}$ For additional discussion of this and other ancillary conditions for choice overload, see Scheibehenne, Greifeneder, and Todd (2010); Chernev, Böckenholt, and Goodman (2010); and Scheibehenne, Greifeneder, and Todd (2011).
} 
these gains resulted primarily from larger choice sets prompting people to rely more heavily on heuristics to find the options that were best for them. Specifically, the authors concluded that "increasing the number of options in a decision problem increases the number of heuristics brought to the task. This challenges the choice overload view that people give up when confronted with too much choice" (p. 524).

Also relevant for considering choice overload in Part D are the conclusions of Scheibehenne, Greifeneder, and Todd (2010) that these null effects are independent of the size of the choice set. That is, they find no evidence of nonlinear effects of adding options to the choice set, as summarized in their Figure 2. As a result, we expect that any effects of choice overload observed under the range of the number of plans available in Part D through 2010 should also apply to much smaller or larger choice sets. It is conceivable that the lack of nonlinearities in these experimental results does not apply to Part D such that choice overload would be evident at much smaller choice set sizes but not at the level of choice set sizes that existed in Part D for 2006 through 2010. In this case, then we should expect that changes in choice set size within our study sample should have no effect on switching rates, and this null effect should be evident regardless of whether the incremental plans are low or high cost.

Regarding the effects of experience, prior research has shown that an individual's likelihood of switching products declines as they gain experience with the product category. This effect has been found in markets for frequently purchased and utilized goods such as laundry detergent (Osborne 2011) and diapers and baby towels (Heilman, Bowman, and Wright 2000), for far less frequently purchased goods such as personal computers (Prince 2011), and for services purchased annually but less frequently utilized such as automobile insurance (Israel 2005a). The precise mechanisms underlying this positive relationship between inertia and experience differ across theoretical models and empirical contexts, but they rely on some combination of increasing switching costs and asymmetric learning. Switching costs arise as consumers make investments in the specific product that they have been purchasing, where those investments do not carry over to the alternatives. Such switching costs may arise from psychological factors or economic factors such as asymmetric learning. Asymmetric learning occurs as consumers gain knowledge of their status quo via their experiences but do not gain knowledge regarding the alternatives (Klemperer 1995; Osborne 2011; Prince 2011).9,10

Other related evidence, however, suggests that consumers' abilities to navigate through such new and growing information markets may themselves grow with experience (Miravete 2003; List 2003, 2004, and 2006; and List and Millimet 2008). In Part D, if experience promotes consumers' ability to find better-matching plans, then we would expect people over time to become more likely to switch away from their status quo plans due to lower search costs (Prince 2011). In contrast, if a

\footnotetext{
${ }^{9}$ An example of this is evident even in the seminal paper on status quo bias by Samuelson and Zeckhauser (1988, p. 37) which states, "Assuming that he or she understands his or her current plan, a reasonable strategy would be to undertake a comparative analysis including only some subset of competing plans (ignoring the others altogether). Thus, the status quo alternative gains a decision advantage by virtue of the asymmetric position it holds in the decision reckoning."

${ }^{10}$ Some of this existing research evaluates and finds that inertia increases with tenure in the status quo plan rather than with experience in the market per se. This focus is partly due to data limitations that allowed the researchers to observe only individuals' tenure at a single firm and not the total extent of their market participation.
} 
person's switching costs or asymmetric learning grow over time, then we expect she would become more likely to remain in her status quo plan. As a second order effect, experience may also enhance or dampen how responsive people are to changes in the relative costs of their status quo plans. Consistent with the prediction that switching costs would dominate, Heiss, McFadden, and Winter (2010, p. 474) concluded that, "there is a lock-in effect, and so it may have been a good strategy for plan providers in this repeated-interaction market to offer cheap plans in the first period and then to increase premiums and/or reduce plan quality over time."

Like automobile insurance studied by Israel (2005a, b), PDPs are purchased annually and may have economic switching costs and asymmetric learning that increase with experience. In Part D such switching costs may exist from factors such as prior authorization requirements for certain drugs or from the hassle costs of establishing new mail order prescriptions. Regarding asymmetric learning, Part D enrollees frequently file claims, unlike auto insurance, potentially facilitating rapid learning about dimensions such as the plan-specific formulary and the quality of customer support. On the other hand, some measures of this information are readily available from sources including the CMS online "plan finder" that facilitates consumers' ability to compare plans. Because of the presence of these sources of information about the alternatives, the role of asymmetric learning in Part D may be minimal. The link between asymmetric knowledge about the status quo and experience may also be weak in Part D: CMS requires plans to notify all of their existing enrollees, regardless of experience levels, of any upcoming changes in their premiums, deductibles, or formulary coverage, including providing a list of specific drugs that will be dropped from the formulary. Presumably this type of statutorily established informational asymmetry may be whittled down by firms' marketing efforts and by the provision of information by intermediaries. On balance, these institutional details suggest that the effects of experience in Part D might diverge from the previously studied contexts where experience has been shown to inhibit switching.

\section{Data and Descriptive Results}

\section{A. Part D Plan Turnover Rates}

Our study combines several rich data sources for 2006-2010 available only from CMS. We begin with the 20 percent sample of Medicare beneficiaries, which is defined as everyone enrolled in Medicare with a randomly assigned Medicare Beneficiary Identity Code that ends with 0 or 5 (Centers for Medicare and Medicaid Services 2014a). To assess the overall level of PDPs' enrollee turnover rates, we create a variable from the Master Beneficiary Summary-Base (A/B/D) files (Centers for Medicare and Medicaid Services 2014c, née the CMS Enhanced Denominator File) that indicates whether each person who started in a PDP without a low-income subsidy was still in the same PDP at the beginning of the following year. ${ }^{11}$ This

\footnotetext{
${ }^{11}$ Due to plan terminations and consolidations, determining whether a person remained in their initial plan is more complex than simply comparing whether the individual had the same contract and plan ID in the subsequent year. We relied on the CMS Plan Information Files (Centers for Medicare and Medicaid Services 2011) and the CMS Plan Crosswalk Files that tracks evolution in a given plan's contract and plan IDs across years to provide an accurate measure of whether the individual was in the same plan over time. Prior to our analysis, the crosswalk files
} 
Table 1-Share of People No Longer Enrolled in Their Original Plan at the Beginning of Each Subsequent Year

\begin{tabular}{lcccc}
\hline \hline \multicolumn{2}{c}{2007} & 2008 & 2009 & 2010 \\
\hline Among nonpoor PDP enrollees who started in & & & \\
2006 & 18.8 & 32.8 & 44.0 & 53.0 \\
2007 & - & 26.2 & 42.6 & 53.8 \\
2008 & - & - & 24.8 & 42.1 \\
2009 & - & - & - & 33.0 \\
\hline
\end{tabular}

variable shows the extent to which enrollees are inert from the plans' perspectives. Low turnover rates would indicate that plans may have substantial opportunity to harvest gains from incumbent enrollees but also substantial incentive to compete for initial enrollment decisions (Dube, Hitsch, and Rossi 2009).

Table 1 reports the overall turnover rates separately by year in which the individual enrolled in any PDP without a low-income subsidy for the first time. Among those who first enrolled in a PDP at any point in 2006, 19 percent were no longer enrolled in their initial plans by January 2007. This climbed to 33 percent by January 2008, 44 by 2009 , and 53 percent were no longer enrolled in their initial PDP at the beginning of 2010. ${ }^{12}$ Similar trends, but with higher turnover levels, are found among those who started in 2007, 2008, and 2009. Within, at most, 12 months of their initial PDP choice, 26 percent of those who started in 2007, 25 percent of those starting in 2008, and 33 percent of those starting in 2009 had already transitioned out of their original PDPs..$^{13}$ Retention rates continued to fall over time so that, by the beginning of 2010, across all four of these cohorts almost exactly half (50.1 percent) were no longer enrolled in their original PDP.

\section{B. The Cost Calculator}

The remainder of this article focuses on individuals' decisions to switch between PDPs. Hence we restrict our analysis to those who were enrolled for the entire year in a single PDP, did not receive a low-income subsidy at any point in the year, were age 65 or higher and alive at the end of the year, did not live in a US territory outside of the 50 states or District of Columbia, and did not have a duplicate entry in any year of the enrollment files. For these individuals, we observe whether they switched between PDPs during each open enrollment period or whether they remained in their status quo PDP.

\footnotetext{
were incomplete and were not developed for conducting longitudinal research. For example, the crosswalks sometimes indicated that a plan was renewed by CMS at the request of the insurer, but the insurer subsequently chose not to offer that plan. In such cases, the plans do not appear in the latter year's Plan Information File, indicating that it was a terminated plan despite the existing crosswalk file's indication that the plan was renewed. We implement logic that capitalizes on all information available in these two files to develop accurate measures of true switching as distinct from non-switching that occurred from mergers or "forced switching" that occurred from terminations. Our efforts created the Part D Plan Crosswalk Extract file used internally within CMS and now available to external researchers.

${ }^{12}$ The 47 percent who remained in their original plan includes those who were still in the same PDP but acquired low-income subsidy status in the interim. We exclude those who had a low-income subsidy at the outset because many of them were assigned to a PDP by CMS and did not choose a plan for themselves.

${ }^{13}$ These non-retention rates include those who left PDPs for various reasons, including death. This is distinct from the measure of switching between PDPs that we use in our empirical analysis, as described below.
} 
One of our central measures of interest is the cost of the individual's status quo plan relative to the available alternatives. To define this we develop and implement a cost calculator that estimates what each person would have spent in each PDP available in her region in each year. This cost calculator is based on institutional knowledge and datasets existing within CMS. It incorporates every aspect of every plan that determines individuals' total out-of-pocket (OOP) costs. These include the plans' formularies and cost sharing structure by pharmacy type; the deductible; coverage of drugs in each phase - below the deductible, below the initial coverage limit, within the gap, and above the catastrophic coverage limit; free first-fill; whether the plan covers statutorily excluded drugs not reimbursed by CMS; and the underlying plan-specific drug prices, which we calculate using the universe (100 percent) of claims from the Prescription Drug Event (PDE) data for each year. ${ }^{14,15}$

We apply this cost calculator to the PDE file that lists every drug claim submitted on behalf of Medicare beneficiaries, including drug identifiers, date filled, gross price, amount paid by the insurer, patient OOP cost, and formulary tier (available only from the research-identifiable file, Centers for Medicare and Medicaid Services 2014d), plus the pharmacy type (merged on from the Pharmacy Characteristics File). By using the claims for each person in the order they were filled, this cost calculator estimates each individual's annual OOP drug spending in each available plan for each year. We measure the total OOP cost of each plan for each person in each year by adding the consumer's annual premiums for each plan from the premium file within the Part D Plan Characteristics Files to the calculated OOP drug spending. ${ }^{16}$ We denote this measure of total OOP cost as $C_{i j t}$ for individual $i$ from choosing plan $j$ that belongs to her choice set in year $t$. We utilize the distribution across plans for a given person and year to determine the difference between the actual chosen plan and the minimum-cost plan, defined as $C_{i t}-\min _{j}\left\{C_{i j t}\right\}$, where $C_{i t}$ is the actual chosen plan in year $t$. This is the realized "above minimum spending." ${ }^{17}$ Likewise for analysis of switching decisions we define $A_{i t}=C_{i j_{t-1} t}-\min _{j}\left\{C_{i j t}\right\}$. We refer to $A_{i t}$ as "the individual's relative cost of staying in her status quo plan" or similar to indicate that this is defined as what she would spend without switching, relative to her lowest cost alternative.

We validate the accuracy of this cost calculator by comparing each individual's actual out-of-pocket (OOP) costs, observed by CMS, with the OOP costs that we calculate for the actual plan, finding correlation coefficients for the two ranging from 0.98 in 2009 to 0.92 in 2006 and 2007. ${ }^{18}$ This high level of accuracy of

\footnotetext{
${ }^{14}$ This highly detailed information on each plan's design is found in the CMS Part D Plan Characteristics Files, which are based on administrative data used to review and approve plans (Centers for Medicare and Medicaid Services 2014a). For example, these files provide the OOP price for every formulary tier, phase, and drug which are key inputs to our cost calculator, as discussed further in the online Appendix. There we also provide details about the development of the plan-specific total drug prices.

${ }^{15}$ For the analysis we utilized the internal CMS data. The majority of this information is available to academic researchers through the Research Identifiable Files, however.

${ }^{16}$ To ensure consistency across every plan in each person's choice set, we use the calculated OOP costs even for the actual plan.

${ }^{17} \mathrm{We}$ do not intend the term above-minimum spending to carry any normative implications. Instead we use it to convey that this variable is concerned with only the total OOP amount that the consumer could have saved by choosing her minimum-cost plan.

${ }^{18}$ By comparison, the cost calculator used in Ketcham et al. (2012) yielded correlations of only 0.80 in 2006 and 0.77 in 2007 . The current cost calculator yields a few cases where the calculated gross spending in the actual plan widely deviates from the actual gross spending. We eliminate these individuals from all years of the data if in any
} 
the cost calculator comes from our ability to incorporate information and institutional knowledge held within CMS that were only partially incorporated into previous cost calculators (Abaluck and Gruber 2011; Ketcham et al. 2012). For example, this includes our ability to generate accurate underlying plan-specific prices, where the cost calculator of Ketcham et al. (2012) relied on a third-party data source (formerly Wolters Kluwer Health, now Symphony Health Solutions) to generate these plan-specific prices. The cost calculator of Abaluck and Gruber (2011) held a given drug's price constant across all plans. Yet allowing drug prices to vary across plans matters substantially, with an average within-person range in total drug spending (the sum of OOP and other payers' spending), holding drug consumption constant and only allowing the plans' drug prices to vary, of $\$ 635$ and an average standard deviation in gross drug spending across plans for a given person-year of $\$ 173$. This contrasts with the calculator developed in Abaluck and Gruber (2011) which imposes $\$ 0$ variance across plans in gross spending for a given person in a given year.

As another specific example of the types of improvements incorporated into this cost calculator, we built into it precise information about gap coverage. In the public use files, gap coverage is presented as a categorical variable. In reality, however, even plans with gap coverage tremendously differ in the extent of coverage in the gap, e.g., some formulary tiers are covered at certain rates in the gap while other tiers may have less or no coverage. We accessed the open text fields provided by the plans themselves to allow the cost calculator to accurately assign each plan's specific cost-sharing rules in the gap for every drug. 19

Several modeling decisions are required to implement this cost calculator. First, as analysts we do not know the quantities or mix of prescriptions each person would have filled in her available but unchosen plans, e.g., due to differences from the actual plan in demand-side (OOP prices) or supply side (e.g., prior authorization requirements) cost controls, or due to differences in pharmacy networks or hassle of getting claims paid. We adopt two different approaches. First, for a given person and year, we hold the drugs constant across every plan in the choice set. We refer to this approach as the "perfectly inelastic" method. Second, we alter the gross and OOP spending to account for price elasticity of demand for drugs. In that approach we rely on the average elasticity for Medicare enrollees of -0.54 estimated by Shea et al. (2007). 20

The second decision that analysts face regards how to measure the information that consumers use to form their expectations about the upcoming year. The context of Part D plan choice incorporates uncertainty about future prescription drug use. In our main approach we use the prescriptions filled in the next year, i.e., the year for which the individual is making an enrollment decision. The models of switching that we implement relying on this approach evaluate consumers' sensitivity to the

single year the dollar difference between their calculated and actual spending as well as the ratio of these two gross spending measures both fall below the 0.1 or above the 99.9 percentile for the year. Investigating the underlying causes of these outliers showed that they were typically due to implausible units dispensed on one claim.

${ }^{19}$ This was required for 2006 only, as in later years this information was embedded within the Research Identifiable File Tier Characteristics Table available to researchers. These details are embedded within the cost calculator code accompanying this article and available through the journal's website.

${ }^{20} \mathrm{~A}$ more extended consideration of these issues is provided in the Appendix of Ketcham et al. (2012). 
Table 2-Trends in Out-OF-Pocket SPEnding

and Above-Minimum Spending AMONg NonPoor PDP ENRollees, 2006-2010

\begin{tabular}{lccccc}
\hline \hline & 2006 & 2007 & 2008 & 2009 & 2010 \\
\hline Total OOP spending on premiums and prescription drugs (\$) & 1,590 & 1,382 & 1,312 & 1,435 & 1,492 \\
Year to year percent change in OOP spending & - & -13.1 & -5.1 & 9.4 & 3.9 \\
Percent change in OOP spending relative to 2006 & - & -13.1 & -17.5 & -9.7 & -6.2 \\
Ex post approach with perfectly inelastic demand for drugs & & & & & \\
OOP Spending in minimum-cost plan (\$) & 1,070 & 1,036 & 1,019 & 1,104 & 1,163 \\
Above-minimum OOP spending (\$) & 520 & 347 & 292 & 331 & 329 \\
Above-minimum OOP spending as percent of total OOP (\%) & 33 & 25 & 22 & 23 & 22 \\
Ex post approach with price elasticity of demand for drugs of -0.54 & & & & & \\
OOP Spending in minimum-cost plan (\$) & 1,235 & 1,145 & 1,078 & 1,153 & 1,217 \\
Above-minimum OOP spending (\$) & 355 & 237 & 234 & 282 & 275 \\
Above-minimum OOP spending as percent of total OOP $(\%)$ & 22 & 17 & 18 & 20 & 18 \\
\hline
\end{tabular}

Note: OOP is out-of-pocket.

actual, realized costs of their status quo plan relative to the lowest cost plan in the upcoming year. We refer to this as the ex post approach. To assess the importance of these key assumptions for our primary results, we also allow for two different possibilities. These are the ex ante or "plan finder" approach and the "rational expectations" approach as described in Section V below.

\section{Trends in Spending, Switching, and Savings from Switching}

The first row of Table 2 reports the total OOP spending in each year as a first measure of how nonpoor PDP enrollees fared over time. The results show a large reduction in individuals' average total OOP costs from 2006 to 2007, amounting to an average decrease of $\$ 208$. These reductions continued and OOP spending fell another $\$ 71$ in 2008 before climbing in both 2009 and 2010, albeit remaining about $\$ 100$ below the 2006 levels.

The remainder of Table 2 reports the trends in the OOP cost of the individual's minimum-cost plan(s) and the trend in above-minimum spending. Because these measures may be sensitive to the assumed price elasticity of demand for drugs, we report them first using the assumption that prescription drug demand is perfectly inelastic, and second assuming an elasticity of -0.54 . As with total OOP spending, the OOP spending under the minimum-cost plan fell each year from 2006-2008 before climbing in both 2009 and 2010.

The net effect of these two trends is captured in the above-minimum OOP spending measures. Above-minimum spending fell sharply from 2006-2007, similar to the results in Ketcham et al. (2012). Under the assumption of perfectly inelastic demand, above-minimum spending fell by $\$ 173$ (33 percent). Above-minimum spending fell by another $\$ 54$ in 2008, yielding a value equal to only 56 percent of the 2006 level. Above-minimum spending climbed in 2009 but plateaued at $\$ 329$ in 2010, still \$191 (37 percent) below the 2006 level and also below the 2007 level. The trend under the assumption of elastic demand is highly similar, albeit with lower levels of above-minimum spending and thus also smaller changes over time. Under both approaches, above-minimum spending as a percent of total OOP spending was at its lowest levels in 2010, matching the lows near 20 percent achieved in 2008. 
To analyze switching decisions, we further limit the sample to those who met the cost calculator criteria for two consecutive years. This ensures that we are comparing two similar sequential open enrollment decisions for full-year non-low-income subsidy coverage because people are likely to make different choices for part-year versus full-year and subsidized versus unsubsidized coverage in ways that would affect switching. Through this restriction and the fact that no switching could occur for 2006, our sample consists of 1,512,275 individuals making 3,960,499 switching decisions, with 433,154 for 2007; 1,141,521 for 2008; 1,183,741 for 2009; and $1,202,083$ for 2010 . The overall rate of switching between PDPs among those who stayed enrolled in a PDP and did not acquire a low-income subsidy is reported in the first row of Table 3 . This rate was 11.7 percent for 2007, fell by nearly one percentage point in 2008, and then remained virtually flat at just under 11 percentage points through 2010. ${ }^{21}$ By comparison, switching rates between nonpoor individuals' initial, partial year of enrollment and their first full year of enrollment were notably higher in almost every year, at 8.5 percent for 2007, 22.1 percent for 2008, 17.6 percent for 2009, and 25.3 percent for 2010 .

With this set of switching decisions, we rely on the cost calculator to measure how much each individual saved as a result of switching. For someone who chose to switch, this is the difference between her total OOP spending in her new plan and what her OOP spending would have been if she had stayed in her status quo plan, i.e., $C_{i t}-C_{i j_{t-1} t}$ where $C_{i j_{t-1} t}$ denotes the OOP spending in year $t$ if the person stayed in her plan from year $t-1$. Because this is a within-person, within-year comparison, it eliminates the effects on OOP spending of all time-varying and time-invariant individual-specific effects including health.

As reported in Table 3, the mean and median savings from switching exceed $\$ 100$ in each year. These savings increased sharply from 2007-2008 and remained high in 2009. They declined in 2010 but still remained above the 2007 levels. These savings accrued to a large majority of those who switched plans, with positive savings for 77-88 percent of them for 2008-2010. These levels are also above 2007, during which 65-66 percent of switchers achieved lower OOP spending as a result of switching. 22

One concern with these overall trends is that the changes in the population enrolled in PDPs over time may mask the average within-person trends. To isolate the average within-person change over time in these trends, we evaluate the subsample that began on January 1, 2006 and remained in the PDP market without a low-income subsidy through the end of 2010. This population is of particular interest because they accrue the most experience in Part D, providing greater ability to evaluate how inertia changes over time.

Table 4 reports this sample's trends in spending, above-minimum spending, switching and savings from switching. Switching rates among this sample were highest in 2010, more than 2 percentage points above their 2009 level and nearly

\footnotetext{
${ }^{21}$ These switching rates are below the overall retention rates reported above because this is restricted to only PDPs' enrollees decisions to switch PDPs during open enrollment between two full years of enrollment in any PDP. This eliminates everyone who left the nonpoor PDP market for various reasons, including acquiring a low-income subsidy, death, and switching to other types of plans.

${ }^{22}$ It is worth noting that these results are based on a demanding analytical standard, as it compares individuals' ex post realized costs in two different plans.
} 
TABLE 3-Switching AND SAVIngS From Switching, 2007-2010

\begin{tabular}{lcccc}
\hline \hline & 2007 & 2008 & 2009 & 2010 \\
\hline Switched between PDPs from the prior year (\%) & 11.7 & 10.9 & 10.6 & 10.7 \\
Ex post approach with perfectly inelastic demand for drugs & & & & 206 \\
$\quad$ Mean savings from switching (\$) & 178 & 256 & 254 & 206 \\
$\quad$ Median savings from switching (\$) & 132 & 223 & 222 & 154 \\
$\quad$ Percent that saved > \$0 from switching (\%) & 66.1 & 81.7 & 86.2 & 77.4 \\
Ex post approach with price elasticity of demand for drugs of -0.54 & 102 & 194 & 195 & 144 \\
$\quad$ Mean savings from switching (\$) & 101 & 158 & 180 & 112 \\
$\quad$ Median savings from switching (\$) & 65.1 & 82.7 & 88.0 & 80.9 \\
Percent that saved > from switching & & & \\
\hline
\end{tabular}

Notes: OOP is out-of-pocket. All values are from the sample that was enrolled in a single PDP without a low-income subsidy for the entire prior year.

Table 4-Spending, Above-Minimum Spending, And Switching AMong the 2006-2010 CohorT

\begin{tabular}{lccccc}
\hline \hline & 2006 & 2007 & 2008 & 2009 & 2010 \\
\hline Switched PDPs from prior year $(\%)$ & - & 11.4 & 11.6 & 9.6 & 11.8 \\
Total OOP spending on premiums and prescription drugs $(\$)$ & 1,519 & 1,504 & 1,438 & 1,597 & 1,691 \\
OOP spending in minimum-cost plan (\$) & 1,006 & 1,138 & 1,115 & 1,238 & 1,331 \\
Above-minimum OOP spending (\$) & 514 & 367 & 324 & 359 & 360 \\
Above-minimum OOP spending as percent of total OOP $(\%)$ & 33.8 & 24.4 & 22.5 & 22.5 & 21.3 \\
\hline
\end{tabular}

Notes: OOP is out-of-pocket. The sample is restricted to the 306,315 that began in the PDP market without a low-income subsidy on January 1, 2006 and remained enrolled in a PDP without a low-income subsidy through December 31, 2010. Minimum and above-minimum spending are defined using the ex post approach and assuming perfectly inelastic demand for drugs.

half a percentage point higher than in 2007. Mean above-minimum spending in 2010 remained $\$ 153$ below its 2006 level and even just below its 2007 level. As with the full sample, above-minimum spending climbed from 2008 to 2009, although in percentage terms, above-minimum spending was lowest in 2010. These trends suggest inertia did not increase over time among this cohort, where these time trends incorporate the effects of individual-specific experience and the overall changes to the market.

To consider additional dynamic aspects of savings from switching, we also establish counterfactual measures for the spending people would have incurred if they stayed in their initially chosen plan for the remainder of their time in the PDP market. This approach allows for savings from switching to accrue to the individual in years even beyond the single year following the switch itself. As shown in Table 5, under the inelastic approach, by 2010 the average annual OOP savings by those who ever switched was $\$ 233$, yielding actual OOP spending 13 percent below what it would have been without any switching. The estimated cumulative savings from switching between PDPs for 2007-2010 exceeds \$1.3 billion, equivalent to 13 percent of the actual cumulative spending by PDP enrollees. Similar patterns with slightly lower magnitudes are observed under the alternative approach of allowing the demand for drugs to be somewhat elastic. ${ }^{23}$

\footnotetext{
${ }^{23}$ These values are calculated for those who switched between two full years of enrollment. As such it represents an underestimate of the true total savings because savings also accrue to those enrolled for only a partial year.
} 
Table 5-Cumulative Switching and Savings From Switching, 2007-2010

\begin{tabular}{|c|c|c|c|c|}
\hline & 2007 & 2008 & 2009 & 2010 \\
\hline $\begin{array}{l}\text { Percent of current enrollees that have ever } \\
\text { previously switched between PDPs }(\%)\end{array}$ & 11.7 & 16.9 & 23.1 & 27.6 \\
\hline $\begin{array}{l}\text { Actual OOP spending by those who ever } \\
\text { previously switched }(\$)\end{array}$ & 1,882 & 1,480 & 1,500 & 1,540 \\
\hline \multicolumn{5}{|l|}{$\begin{array}{l}\text { Ex post approach with perfectly inelastic } \\
\text { demand for drugs }\end{array}$} \\
\hline $\begin{array}{l}\text { OOP spending if stayed in original plan } \\
\text { and never switched }(\$)\end{array}$ & 2,062 & 1,687 & 1,725 & 1,773 \\
\hline $\begin{array}{l}\text { Annual savings by current enrollees who ever } \\
\text { previously switched }(\$)\end{array}$ & 180 & 207 & 225 & 233 \\
\hline Savings as a percent of total OOP spending (\%) & 9.6 & 14.0 & 15.0 & 15.1 \\
\hline Total non-subsidy PDP full year enrollees & $7,462,806$ & $7,743,191$ & $7,790,845$ & $7,787,562$ \\
\hline Annual savings from cumulative switching (\$) & $157,306,398$ & $271,298,803$ & $405,055,147$ & $500,802,537$ \\
\hline Total cumulative savings from switching $(\$)$ & $157,306,398$ & $428,605,201$ & $833,660,347$ & $1,334,462,885$ \\
\hline \multicolumn{5}{|l|}{$\begin{array}{l}\text { Ex post approach with price elasticity of } \\
\text { demand for drugs of }-0.54\end{array}$} \\
\hline $\begin{array}{l}\text { OOP spending if stayed in original plan } \\
\text { and never switched }(\$)\end{array}$ & 1,987 & 1,650 & 1,686 & 1,734 \\
\hline $\begin{array}{l}\text { Annual savings by current enrollees who ever } \\
\text { previously switched }(\$)\end{array}$ & 105 & 170 & 186 & 194 \\
\hline Savings as a percent of total OOP spending $(\%)$ & 5.6 & 11.5 & 12.4 & 12.6 \\
\hline Total non-subsidy PDP full year enrollees & $7,462,806$ & 7,743,191 & $7,790,845$ & 7,787,562 \\
\hline Annual savings from cumulative switching (\$) & $91,820,275$ & $222,880,629$ & $334,867,424$ & $416,977,220$ \\
\hline Total cumulative savings from switching $(\$)$ & $91,820,275$ & $314,700,905$ & $649,568,329$ & $1,066,545,549$ \\
\hline
\end{tabular}

Note: OOP is out-of-pocket.

\section{Variables for Number of Plans and Experience}

We rely on two distinct measures of the number of plans to evaluate the role of choice overload in people's switching decisions. First, we use the total number of plans available in the region regardless of their relative costs to the individual. This is measured by counting the number of unique plan IDs listed for PDPs (and excluding employer plans) offered in each region and each year. ${ }^{24}$ Second, we use the results from the cost calculator to count the number of plans by their relative costs. We define this as the number of plans that are within $\$ 100$ of the person's minimum-cost plan, within $\$ 100-\$ 200$ of the minimum, $\$ 200-\$ 300, \$ 300-\$ 400$, $\$ 400-\$ 500$, and more than $\$ 500$. In contrast with the overall plan count, which is defined at the region level, this is an individual-specific variable with variation across individuals within a given region and year.

Table 6 reports the overall number of plans and the number of plans by relative cost category using the ex post approach. To streamline the presentation of results, here we report only the count by cost assuming a price elasticity of demand for drugs of -0.54 . Consistent with the change in enforcement announced by CMS for 2008 described above, the strong surge in the number of plans available in 2007 was followed by a decline in 2008 . This decline continued through 2010 , dropping from a high of 56 in 2007 to 50 in 2009 and to 46 in 2010. These declines from 2007-2010 appear concentrated among the lower cost categories, with the largest

\footnotetext{
${ }^{24}$ Employer plans are not available to people who were not employees of the particular firm.
} 
Table 6-Average Number of Prescription Drug Plans Available to the Study Sample, Overall and by Individual-SPECIFIC Relative Cost Categories

\begin{tabular}{|c|c|c|c|c|c|c|c|c|}
\hline & \multirow[b]{2}{*}{ Overall } & \multirow[b]{2}{*}{2006} & \multirow[b]{2}{*}{2007} & \multirow[b]{2}{*}{2008} & \multirow[b]{2}{*}{2009} & \multirow[b]{2}{*}{2010} & \multicolumn{2}{|c|}{ Average within-person } \\
\hline & & & & & & & Minimum & Maximum \\
\hline Total stand-alone plans available & 51.1 & 43.1 & 55.8 & 54.5 & 50.2 & 47.1 & 46.3 & 55.3 \\
\hline \multicolumn{9}{|l|}{ Number of plans available within } \\
\hline$\$ 100$ of minimum & 4.8 & 3.0 & 6.2 & 5.8 & 4.0 & 4.0 & 2.2 & 8.2 \\
\hline$\$ 100-200$ of minimum & 8.8 & 4.4 & 11.3 & 10.6 & 7.6 & 7.3 & 4.6 & 13.6 \\
\hline$\$ 200-300$ of minimum & 10.4 & 6.5 & 12.6 & 10.8 & 10.4 & 9.3 & 6.3 & 14.5 \\
\hline$\$ 300-400$ of minimum & 8.6 & 7.2 & 10.0 & 8.9 & 8.4 & 7.6 & 5.2 & 12.1 \\
\hline$\$ 400-500$ of minimum & 5.5 & 6.2 & 5.8 & 5.2 & 5.6 & 5.4 & 2.9 & 8.6 \\
\hline$>\$ 500$ of minimum & 13.0 & 16.0 & 9.8 & 13.2 & 14.3 & 13.5 & 7.6 & 19.4 \\
\hline
\end{tabular}

Notes: The set of available prescription drug plans excludes employer-sponsored plans because those are not open to those not employed by the firm. The count by category of relative costs are from the ex post version assuming a price elasticity of demand for drugs of -0.54 .

percent reductions in the two lowest cost categories (35 percent). In contrast, the highest cost category saw an increase in the number of plans over that period. The last two columns of this table show the averages of the minimums, maximums, and within-person ranges of these variables. This is important because our identification for empirically testing the choice overload hypothesis relies on such within-person variation.

The final main variable of interest is experience. We define this as the cumulative number of months with coverage in a PDP without a low-income subsidy. We eliminate time in a PDP with a low-income subsidy for two reasons. First, such enrollees are auto-assigned to a benchmark plan and thus may not have any experience searching for plans. Second, the OOP cost-sharing structure for on-formulary drugs is substantially different when a person has a low-income subsidy, so that such experience likely has little informative value to consumers. We analyze the effects of total experience in the PDP market rather than the tenure in the status quo plan. Much of the prior research from other contexts used the cumulative time in the status quo because the available data did not permit the authors to observe total time in the market. Given that we can observe total experience here, we rely on it exclusively because tenure in the status quo plan is endogenous, as discussed extensively in Israel (2005b). ${ }^{25}$ The average experience of our study sample climbed each year, beginning with exactly 12 months for everyone in the 2007 sample, to 21 months in 2008, 31 months in 2009, and 40 months in 2010.

\section{E. Demographics, Health, and Other Variables}

We link on several CMS datasets to determine each individual's characteristics at each point in time. The individual's region, age (held constant as age at the end of 2010), sex, and race (defined using the Research Triangle Institute methodology developed by Eicheldinger and Bonito 2008) are provided from the Beneficiary Summary File (Centers for Medicare and Medicaid Services 2014b). Measures of

\footnotetext{
${ }^{25}$ The number of months in the status quo plan and the total months of experience in the PDP market have a correlation coefficient of 0.88 .
} 
each individual's health are provided through the Beneficiary Annual Summary File (BASF), from which we measure the total reimbursement (defined as the sum of what Medicare paid, what the individual paid, and what any secondary insurers paid) for the beneficiary for hospital inpatient stays, for physician services, and for all other non-Part D spending (Centers for Medicare and Medicaid Services 2014a). Other health controls we incorporate from the BASF are the number of hospital inpatient admissions, outpatient visits, skilled nursing facility days, and physician office visits. Additionally, the Chronic Condition Data Warehouse (CCW) provides indicator variables for 21 different clinical indications for 2005-2010, which we collapse into 16 different categories (Centers for Medicare and Medicaid Services 2014a). ${ }^{26}$ The list of illnesses and their prevalence by year are presented in the online Appendix, as are the means of the other variables used but not reported elsewhere in this article.

\section{Switching and Choice Overload}

In this section we evaluate the role of choice overload in explaining individuals' switching decisions. Our approach relies on the within-person variation over time in the number of plans available to her. Our specific objectives are to determine how individual decisions to switch plans depend on the individual's relative costs from remaining in the status quo plan and the number of available plans. That is, we evaluate two pathways by which choice overload may increase inertia. To accomplish this we estimate linear probability models of the form

$$
S_{i t}=\theta_{t}+\theta_{i}+\alpha_{1} A_{i t}+\alpha_{2} N_{i t}+\alpha_{3} H_{i t}+u_{i t},
$$

where $S_{i t}$ equals 100 if the individual switched for year $t$ and 0 otherwise, $\theta_{\mathbf{t}}$ correspond to year fixed effects, $\theta_{i}$ is an individual-specific time invariant unobservable, $A_{i t}$ is the person's above-minimum spending in units of $\$ 100$ if she remains in her status quo plan and $H_{i t}$ represents time-varying measures of the individual's health as described in Section II. In the first specification, $N_{i t}$ is the number of plans available in the region and year. In the second specification, it is a vector of variables that count how many plans are within each category of OOP spending relative to the minimum-cost plan, as listed above. The coefficients on these main effects for $N_{i t}$ test the prediction of choice overload that larger choice sets will inhibit switching. To account for the fact that the number of available plans is determined at the regionyear level, we estimate every model using the cluster-robust variance estimator clustered at the region-year level (Cameron, Gelbach, and Miller 2008). We implement this linear specification as opposed to index models such as logit or probit due to the incidental parameters problem first reported by Neyman and Scott (1948).27

\footnotetext{
${ }^{26}$ The CCW methodology utilizes peer-reviewed research to identify specific ICD-9, CPT4, and HCPCS codes indicating the presence of a diagnosis for each condition, as described online, http://www.ccwdata.org/chronic-conditions/index.htm. The CCW creates these indicators by using information from the individual's Medicare Part A and Part B claims.

${ }^{27}$ This has been studied further by Nerlove (1967, 1971), Heckman (1981), Abrevaya (1997), Katz (2001), and Greene (2004). This problem makes both the fixed effects and the parameters of the index inconsistent in those models when the individual heterogeneity is left completely unrestricted. Although it is possible to estimate fixed effects logit models with an unrestricted distribution of the unobserved characteristics, we see two drawbacks
} 
Table 7-Parameter Estimates from Models of Switching Prescription Drug Plans, 2007-2010

\begin{tabular}{|c|c|c|c|c|c|c|c|c|}
\hline \multirow[b]{3}{*}{$\begin{array}{l}\text { Above-minimum spending if stay in status } \\
\text { quo plan }(\$ 100 \mathrm{~s})\end{array}$} & \multicolumn{4}{|c|}{ Number of plans overall } & \multicolumn{4}{|c|}{ Number of plans by cost } \\
\hline & \multicolumn{2}{|c|}{ No interactions } & \multicolumn{2}{|c|}{ Interactions } & \multicolumn{2}{|c|}{ No interactions } & \multicolumn{2}{|c|}{ Interactions } \\
\hline & 2.88 & {$[0.39] * * *$} & 4.99 & {$[2.16] * *$} & 4.03 & {$[0.48] * * *$} & 6.80 & {$[2.04] * * *$} \\
\hline $\begin{array}{l}\text { Number of available plans } \\
\text { Above-minimum spending if stay }(\$ 100 \mathrm{~s}) \\
\times \text { number of available plans }\end{array}$ & 0.39 & {$[0.31]$} & $\begin{array}{r}0.50 \\
-0.04\end{array}$ & $\begin{array}{l}{[0.34]} \\
{[0.04]}\end{array}$ & & & & \\
\hline $\begin{array}{l}\text { Number of available plans within } \\
\$ 100 \text { of minimum } \\
\$ 100-200 \text { of minimum } \\
\$ 200-300 \text { of minimum } \\
\$ 300-400 \text { of minimum } \\
\$ 400-500 \text { of minimum } \\
>\$ 500 \text { of minimum }\end{array}$ & & & & & $\begin{array}{l}0.60 \\
0.61 \\
0.54 \\
0.41 \\
0.43 \\
0.00\end{array}$ & $\begin{array}{l}{[0.25]^{* *}} \\
{[0.28]^{* *}} \\
{[0.26]^{* *}} \\
{[0.24]^{*}} \\
{[0.26]^{*}} \\
{[0.24]^{*}}\end{array}$ & $\begin{array}{l}0.90 \\
0.60 \\
0.43 \\
0.32 \\
0.36 \\
0.58\end{array}$ & $\begin{array}{l}{[0.31]^{* * *}} \\
{[0.31]^{*}} \\
{[0.30]} \\
{[0.27]} \\
{[0.31]} \\
{[0.28]^{* *}}\end{array}$ \\
\hline $\begin{array}{l}\text { Above-minimum spending if stay }(\$ 100 s) \times \\
\$ 100 \text { of minimum } \\
\$ 100-200 \text { of minimum } \\
\$ 200-300 \text { of minimum } \\
\$ 300-400 \text { of minimum } \\
\$ 400-500 \text { of minimum } \\
>\$ 500 \text { of minimum }\end{array}$ & numbe & of availab & ble plan & within & & & $\begin{array}{r}-0.08 \\
0.03 \\
0.03 \\
-0.01 \\
-0.02 \\
-0.13\end{array}$ & $\begin{array}{l}{[0.05]} \\
{[0.04]} \\
{[0.04]} \\
{[0.04]} \\
{[0.04]} \\
{[0.04]^{* * *}}\end{array}$ \\
\hline $\begin{array}{l}2008 \\
2009 \\
2010\end{array}$ & $\begin{array}{r}0.10 \\
-0.20 \\
1.16\end{array}$ & $\begin{array}{l}{[1.50]} \\
{[2.23]} \\
{[3.42}\end{array}$ & $\begin{array}{r}0.11 \\
-0.20 \\
1.09\end{array}$ & $\begin{array}{l}{[1.49]} \\
{[2.24]} \\
{[3.45}\end{array}$ & $\begin{array}{l}1.74 \\
2.32 \\
3.64\end{array}$ & $\begin{array}{l}{[1.55]} \\
{[2.06]} \\
{[2.94}\end{array}$ & $\begin{array}{r}-0.08 \\
-0.02 \\
1.55\end{array}$ & $\begin{array}{l}{[1.67]} \\
{[2.26]} \\
{[3.18}\end{array}$ \\
\hline
\end{tabular}

Notes: Observations: 3,645,570. Standard errors from cluster-robust variance estimator clustered at the regionyear level are in brackets. All models also include individual fixed effects and controls for time-varying health. The number of plans by cost category and above-minimum spending in the status quo plan are defined using the ex post approach and assuming a price elasticity of demand for drugs of -0.54 .

*** Significant at the 1 percent level.

** Significant at the 5 percent level.

* Significant at the 10 percent level.

To this base model we add an interaction term to provide a test of the second order prediction about how choice overload affects individuals' decisions to switch plans. Specifically, we estimate linear probability models

$$
S_{i t}=\theta_{t}+\theta_{i}+\alpha_{1} A_{i t}+\alpha_{2} N_{i t}+\alpha_{3} H_{i t}+\alpha_{4} A_{i t} \times N_{i t}+u_{i t} .
$$

The interaction term $A_{i t} \times N_{i t}$ provides a test whether adding more options decreases individuals' responsiveness to changes in the above-minimum spending they would incur if they remain in their status quo plans.

Table 7 shows the results from these models from the ex post elastic version. The results from alternative modeling approaches are reported in Section V. Across all four models, the relative cost of the status quo plan in the upcoming year influences individuals' switching decisions. Specifically, each additional $\$ 100$ of above-minimum spending by remaining in the status quo plan increases the conditional probability of switching by $2.9-4.0$ percentage points.

relative to the linear probability model. First, it can only be estimated on individuals with variation in the switching variable, i.e., those who switched in at least one year but not every year. This is a nonrepresentative sample and would yield overestimates of the true marginal effects of the independent variables. Second, obtaining the marginal effects of interest requires further assumptions about the value of the unobserved effects, which defeats the purpose of leaving that distribution unrestricted. 
Regarding the main prediction of choice overload's effects, the results in the first and third models indicate that adding all but the most expensive plans increases switching rates. Each additional available plan within $\$ 100$ of the minimum increases switching by 0.6 percentage points. These positive effects persist but diminish across each relative cost category except the most expensive category. Adding more of the relatively worst plans to the choice set, those that would cost the individual more than $\$ 500$ above her minimum-cost option, does not diminish switching. This is contrary to expectations under choice overload. Instead of promoting inertia, these results indicate that adding such cost-dominated options is simply irrelevant to individuals' decisions to switch plans, e.g., because such plans are not part of individuals' consideration sets. ${ }^{28}$

This null effect of adding the most expensive plans carries over to the results for the single measure of the total number of plans. As shown in Table 6, most of the within-person variation in the number of plans occurs from changes in this highest cost category. As a result, the 95 percent confidence interval on the effect of the total number of plans ranges from -0.2 to 1.0 with a point estimate indicating that each additional plan increases switching rates by 0.4 percentage points in the first model and 0.5 percentage points in the second. To assess directly how expanding the choice set by adding all but the most expensive plans affects switching, we reestimate equation (1) but using three alternative groupings of plans by their cost to the individual: the number of plans within $\$ 500$ of the minimum versus above $\$ 500$, i.e., grouping together all but the highest cost category in the third model; the number within $\$ 400$ and greater than $\$ 400$; and the number within $\$ 300$ versus greater than $\$ 300$.

Table 8 presents results from these alternative groupings. All three approaches confirm that having more plans available increases switching unless the incremental plans are relatively expensive for the individual. For example, the results under "Model A" indicate that as an individual's choice set size grows due to adding one more plan within $\$ 500$ of her minimum-cost plan, she becomes 0.5 percentage points more likely to switch. In contrast, each additional plan with higher costs to her has no effect on her likelihood of switching.

The second and fourth models in Table 7 provide evidence regarding the second order choice overload effects of adding plans to the choice set. Neither set of results indicates that adding plans dampens individuals' responsiveness to their status quo plans' costs. The only statistically significant effect that appears is for expanding the number of the most expensive plans, but the magnitude is minuscule and vastly outweighed by the main effect of the cost of staying in the status quo plan. ${ }^{29}$

\footnotetext{
${ }^{28}$ A referee suggested an additional evaluation that splits the sample based on total drug spending to determine if the differences across the plan cost categories are due to differences between people. The specific question is whether the higher switching in response to adding lower cost plans was driven entirely by individuals with low drug consumption. The underlying hypothesis is that their task of comparing plans may be simpler than those with higher drug spending. To investigate this we split the sample into tertiles by average annual gross drug spending. All three tertiles exhibit within-person variation in the number of plans in each cost category, e.g., the highest tertile of drug spending had an average within person change of 5.2 plans within $\$ 100$ of the minimum, compared to an average for the overall sample of 6.0. More importantly, the economically and statistically significant increase in switching due to adding more low cost options and the null effect of adding more high cost options is evident in the estimated parameters for all three tertiles.

${ }^{29}$ For example, adding one more plan costing more than $\$ 500$ above the lowest cost plan reduces the responsiveness to $\$ 200$ higher in above-minimum spending in the status quo plan by 0.3 percentage points, but the net effect of $\$ 200$ greater overspending is to increase switching by 13.9 percentage points. Likewise, incorporating the main
} 
Table 8-Parameter Estimates from Models of Switching with Alternative Categories of the Number of Plans by Cost, 2007-2010

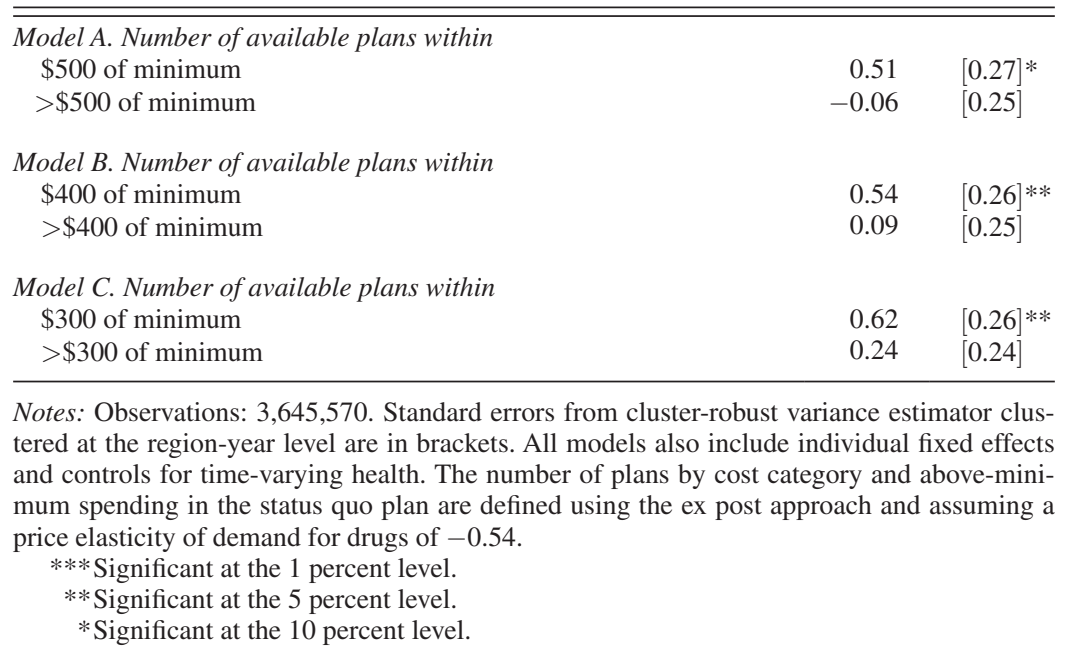

Likewise this lack of significance on the interaction terms in these models also indicates that the marginal effects of adding plans do not change with the choice set size. That is, it provides no evidence for the presence of non-linearities that would result in people becoming less responsive to their status quo plans' costs as the number of plans increases. Finally, across all four models the results show no statistically significant differences in conditional switching rates across the years in our sample. This provides evidence that inertia did not increase over time, which we investigate further in the next section. ${ }^{30}$

\section{Switching and Experience}

We extend the model to evaluate how individuals' switching decisions evolve over time. Specifically, we allow the responsiveness to the status quo plans' relative costs to differ across years as well as with individual-specific experience. We also account for the fact that these within-person changes may be correlated with other factors such as changes in health. Hence we add three interaction terms to the switching model

$$
\begin{aligned}
S_{i t}= & \theta_{t}+\theta_{i}+\alpha_{1} A_{i t}+\alpha_{2} A_{i t} \times \theta_{t}+\alpha_{2} N_{i t}+\alpha_{3} H_{i t} \\
& +\alpha_{4} A_{i t} \times N_{i t}+\alpha_{5} A_{i t} \times E_{i t}+\alpha_{6} A_{i t} \times H_{i t}+u_{i t} .
\end{aligned}
$$

effect shows that adding plans more than $\$ 500$ above the lowest cost plan yields effects statistically indistinguishable from zero across almost the entire relevant range.

${ }^{30}$ To evaluate whether the results in this section are sensitive to the chosen sample definition, we reestimated the models excluding switching decisions that did not meet a few additional criteria. These criteria eliminated decisions by anyone who moved between regions at any point from 2006-2010, the few instances where a "forced switch" occurred as a result of their status quo plans exiting the market, and decisions by those who later left the sample for various reasons, including death, acquiring a low-income subsidy, or switching to a Medicare Advantage plan. The results are virtually identical to those for the full sample. 
The first interaction term, $A_{i t} \times \theta_{\mathbf{t}}$, allows the effect of above-minimum spending to vary within person across years and the interaction term $A_{i t} \times E_{i t}$ allows it to vary within person with experience (defined as the person's cumulative months in a PDP without a low-income subsidy). ${ }^{31,32}$

To mitigate any potential for bias due to heterogeneity in individual-specific responsiveness due to unobserved factors, we include a third interaction, $A_{i t} \times H_{i t}$. Rather than interacting the full set of $H_{i t}$ variables, we restrict the interaction to total current drug consumption, measured as gross spending on prescription drugs (in $\$ 1,000$ s) as an additional measure of relevant health; age in 2010 (as such it does not vary within individual over time, to limit collinearity with experience); and having been diagnosed with Alzheimer's disease or related dementia because the prevalence of these illnesses is known to increase with age (Querfurth and LaFerla 2010). As one specific example of the concerns this interaction accounts for is the possibility that those with greater experience were more responsive simply because their drug spending was higher, providing them with greater financial incentives to switch due to greater potential savings. ${ }^{33}$ Finally, to address any concerns that unobserved differences in responsiveness may still exist and be associated with experience due to the timing of the initial enrollment decisions, we re-estimated the model but excluded from all years those individuals who initially joined the PDP market during the extended initial open enrollment period of January 2, 2006 through May 15, 2006.

Table 9 reports the results. For each year 2008-2010, individuals were more responsive to their status quo plan's relative costs than they were in 2007. No statistically significant differences in responsiveness exist between 2008, 2009, and 2010. Offsetting these year-specific gains, however, is the effect of individual-specific amount of time in the PDP market. Conditional on the year-specific effects, having more experience reduced individuals' responsiveness to their status quo plan's relative costs. As an example of the magnitude of this effect, an additional 12 months of experience reduces the responsiveness to a $\$ 200$ increase in the status quo plan's relative costs by 1.4 percentage points. Drawing causal inferences from this hinges on how well the model has controlled for other individual-specific time-varying factors that may affect responsiveness to the status quo plans' costs. The coefficients on the additional interaction terms show statistically significant differences in

\footnotetext{
${ }^{31}$ Because our specifications include both individual-specific fixed effects and year fixed effects, we cannot also include a main effect for months of experience in Part D. Months of experience is a perfectly linear combination of the year indicators and individual fixed effects because it increases by exactly 12 months each year for each person in the sample.

${ }^{32}$ In unreported results we also implemented models with the three-way interaction terms, $A_{i t} \times \theta_{t} \times E_{i t}$, and found that the differences across experience levels in terms of responsiveness to the status quo plans' costs was very similar across years.

${ }^{33}$ The identification and interpretation of the estimated effects of experience are influenced by our approach. Due to our sample inclusion criteria and incorporation of individual-specific effects, the effects of individual-specific experience are identified only in 2008-2010. This is a result of the fact that we only evaluate decisions to switch for 2007 by those who were enrolled for all of 2006. Hence no within-year variation in experience exists in our sample until 2008. One implication of this limitation is we cannot directly evaluate the role of learning in explaining the reductions from 2006 to 2007 while also accounting for individual-specific unobserved heterogeneity. A second concern may be that our estimates would miss the effects of experience if they occur primarily within the first partial year of enrollment. To evaluate this we implemented these models but included the switching decisions between a partial year of enrollment and a full year of enrollment. The coefficient on the experience interaction using this larger sample is virtually identical to that reported here.
} 
Table 9-Parameter Estimates From Models of Switching THAT Allow FOR DifFERENCES OVER Time, 2007-2010

\begin{tabular}{|c|c|c|c|c|c|c|}
\hline \multirow[b]{3}{*}{$\begin{array}{l}\text { Above-minimum spending if stay in } \\
\text { status quo plan }(\$ 100 \mathrm{~s})\end{array}$} & \multicolumn{4}{|c|}{ Number of plans overall } & \multicolumn{2}{|c|}{$\begin{array}{l}\text { Number of plans } \\
\text { by cost }\end{array}$} \\
\hline & \multicolumn{2}{|c|}{ Full sample } & \multicolumn{2}{|c|}{$\begin{array}{l}\text { Excluding early } \\
2006 \text { enrollees }\end{array}$} & \multicolumn{2}{|c|}{ Full sample } \\
\hline & 4.08 & {$[3.88]$} & 2.16 & {$[4.10]$} & 2.21 & {$[3.72]$} \\
\hline $\begin{array}{l}\text { Above-minimum spending if stay } \\
(\$ 100 \mathrm{~s}) \times 2008\end{array}$ & 3.21 & {$[0.43]^{* * *}$} & 3.10 & {$[0.45]^{* * *}$} & 3.36 & {$[0.53] * * *$} \\
\hline $\begin{array}{l}\text { Above-minimum spending if stay } \\
(\$ 100 \mathrm{~s}) \times 2009\end{array}$ & 3.85 & {$[0.70]^{* * *}$} & 3.78 & {$[0.65]^{* * *}$} & 4.62 & {$[0.70] * * *$} \\
\hline $\begin{array}{l}\text { Above-minimum spending if stay } \\
(\$ 100 \mathrm{~s}) \times 2010\end{array}$ & 3.79 & {$[1.17]^{* * *}$} & 3.74 & {$[1.13]^{* * *}$} & 4.86 & {$[1.13] * * *$} \\
\hline $\begin{array}{l}\text { Above-minimum spending if stay } \\
(\$ 100 \mathrm{~s}) \times \text { months of experience }\end{array}$ & -0.06 & {$[0.02]^{* *}$} & -0.06 & {$[0.02]^{* * *}$} & -0.07 & {$[0.02] * * *$} \\
\hline $\begin{array}{l}\text { Above-minimum spending if stay } \\
(\$ 100 \mathrm{~s}) \times \text { age in } 2010\end{array}$ & -0.25 & {$[0.05] * * *$} & -0.21 & {$[0.06] * * *$} & -0.22 & {$[0.04] * * *$} \\
\hline $\begin{array}{l}\text { Above-minimum spending if stay } \\
(\$ 100 \mathrm{~s}) \times \text { has Alzheimer's disease }\end{array}$ & -0.72 & {$[0.11] * * *$} & -0.56 & {$[0.15]^{* * *}$} & -0.79 & {$[0.09] * * *$} \\
\hline $\begin{array}{l}\text { Above-minimum spending if stay } \\
(\$ 100 \mathrm{~s}) \times \text { current gross drug } \\
\text { spending }(\$ 1,000 \mathrm{~s})\end{array}$ & -0.03 & {$[0.01] * * *$} & 0.00 & {$[0.00]^{* *}$} & -0.02 & {$[0.01]^{* *}$} \\
\hline Current gross drug spending $(\$ 1,000 \mathrm{~s})$ & 0.22 & {$[0.06] * * *$} & 0.15 & {$[0.06] * * *$} & 0.27 & {$[0.05] * * *$} \\
\hline Number of available plans & 0.41 & {$[0.34]$} & 0.32 & {$[0.39]$} & & \\
\hline $\begin{array}{l}\text { Above-minimum spending if stay } \\
\quad(\$ 100 \mathrm{~s}) \times \text { number of available plans }\end{array}$ & -0.02 & {$[0.07]$} & 0.01 & {$[0.07]$} & & \\
\hline \multicolumn{7}{|l|}{ Number of available plans within } \\
\hline$\$ 100$ of minimum & & & & & 0.63 & {$[0.30] * *$} \\
\hline$\$ 100-200$ of minimum & & & & & 0.36 & {$[0.30]$} \\
\hline$\$ 200-300$ of minimum & & & & & 0.13 & {$[0.29]$} \\
\hline$\$ 300-400$ of minimum & & & & & 0.06 & {$[0.26]$} \\
\hline$\$ 400-500$ of minimum & & & & & 0.11 & {$[0.29]$} \\
\hline$>\$ 500$ of minimum & & & & & 0.33 & {$[0.28]$} \\
\hline \multicolumn{7}{|c|}{ Above-minimum spending if stay $\times$ number of available plans within } \\
\hline$\$ 100$ of minimum & & & & & 0.01 & {$[0.07]$} \\
\hline$\$ 100-200$ of minimum & & & & & 0.11 & {$[0.07]$} \\
\hline$\$ 200-300$ of minimum & & & & & 0.12 & {$[0.07]^{*}$} \\
\hline$\$ 300-400$ of minimum & & & & & 0.07 & {$[0.06]$} \\
\hline$\$ 400-500$ of minimum & & & & & 0.05 & {$[0.06]$} \\
\hline$>\$ 500$ of minimum & & & & & -0.05 & {$[0.07]$} \\
\hline 2008 & -6.53 & {$[1.75] * * *$} & -5.64 & {$[1.88] * * *$} & -6.88 & {$[1.77] * * *$} \\
\hline 2009 & -7.33 & {$[2.11] * * *$} & -7.31 & {$[2.20] * * *$} & -8.68 & {$[1.93] * * *$} \\
\hline 2010 & -3.78 & {$[3.36]$} & -2.79 & {$[3.83]$} & -5.32 & {$[2.96] *$} \\
\hline Observations & 3,6 &, 570 & 2,07 & 059 & 3,6 &, 570 \\
\hline
\end{tabular}

Notes: Standard errors from cluster-robust variance estimator clustered at the region-year level are in brackets. All models include year fixed effects, individual fixed effects, and controls for time-varying health. The results in the column "excluding early 2006 enrollees" exclude from all years those who first entered the PDP market from January 2 through May 15, 2006. The number of plans by cost category and above-minimum spending in the status quo plan are defined using the ex post approach and assuming a price elasticity of demand for drugs of -0.54 .

*** Significant at the 1 percent level.

** Significant at the 5 percent level.

* Significant at the 10 percent level.

these elasticities across the three observed time-varying characteristics we include. Specifically, the results show that those who are older are less responsive to the costs of staying in their status quo (consistent with the model in Stigler and Becker 1977), 
Table 10-Estimated Conditional Within-Person Difference in Switching Between 2007 and Later Years in Response to an Increase in the Status Quo Plan's Costs

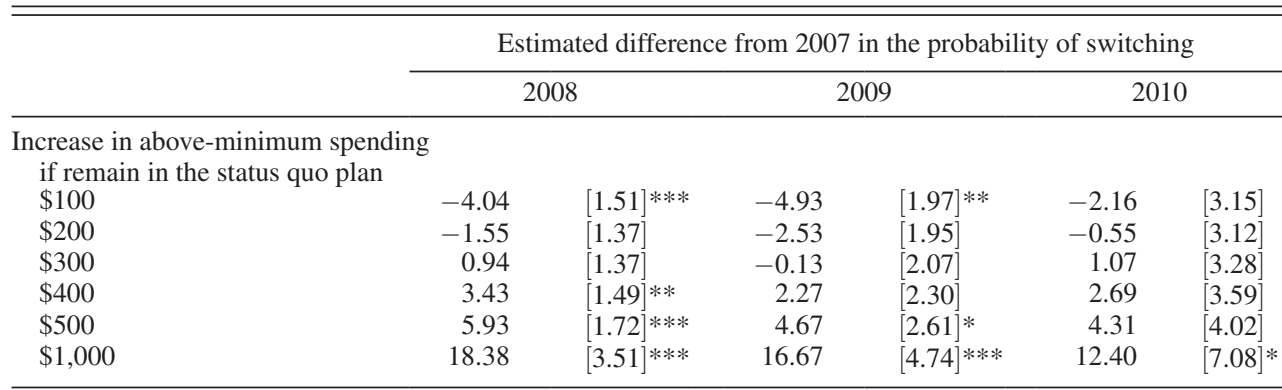

Notes: Estimates are based on the results from the first model provided in the preceding table. Standard errors from cluster-robust variance estimator clustered at the region-year level are in brackets.

*** Significant at the 1 percent level.

** Significant at the 5 percent level.

*Significant at the 10 percent level.

those with Alzheimer's disease or other dementia are less responsive, and those with higher levels of drug spending are less responsive but more likely to switch overall. As evident from comparing the first two columns of results, all of these results are virtually identical between the full sample and the sample that excludes those who waited to join a PDP during the extended initial open enrollment period. ${ }^{34}$

To estimate the total within-person change in responsiveness over time we utilize the year main effects and the coefficients on $A_{i t} \times \theta_{t}$ and $A_{i t} \times E_{i t}$. The results show that over time individuals became more responsive to higher levels of increases in their status quo plans' relative costs but less responsive to lower levels. Table 10 provides results based on the coefficients in the first column in Table 9. For example, people were 4.0 percentage points less likely to switch in response to a $\$ 100$ increase (relative to her individual-specific mean above-minimum spending from staying in her status quo plan) in 2008 than they were in $2007(p<0.01)$. In contrast, they were no different between 2007 and later years in their responsiveness to $\$ 200$ or $\$ 300$ increases. They were 5.9 percentage points more likely to switch in 2008 than 2007 in response to a $\$ 500$ increase $(p<0.01)$. All of the differences diminish by 2010, so that the only remaining difference from 2007 significant at the 10 percent level is that people were 12.4 percentage points more likely in 2010 to switch out of their status quo plan in response to a $\$ 1,000$ increase relative to their minimum-cost plan. This increased responsiveness to larger increases relative to 2007 suggests that over time, people did not become more inert or pay less attention to their status quo plans' relative costs.

\section{Results from Alternative Modeling Approaches}

In this section we evaluate the extent to which the results depend on the decisions that analysts must make about individuals' expectations regarding the relative

\footnotetext{
${ }^{34}$ As a final consideration of differences across cohorts, we estimated the model but restricted to the sample that joined the PDP market on January 1, 2006 and remained in it through the end of 2010, i.e., the same sample as used in Table 4. For this sample we cannot separately identify year and experience effects, so we exclude the $A_{i t} \times E_{i t}$ term. The results confirm that this cohort was more responsive to all increases of about $\$ 300$ or more in their status quo plans' costs in 2008-2009 than in 2007 but had no statistically significant differences between 2010 and 2007.
} 
Table 11-Parameter Estimates from Ex Post Models of Switching Assuming Perfectly Inelastic Demand for Drugs, 2007-2010

\begin{tabular}{|c|c|c|c|c|c|c|c|c|}
\hline \multirow[b]{3}{*}{$\begin{array}{l}\text { Above-minimum spending if stay in } \\
\text { status quo plan }(\$ 100 \mathrm{~s})\end{array}$} & \multicolumn{4}{|c|}{ Number of plans overall } & \multicolumn{4}{|c|}{ Number of plans by cost } \\
\hline & \multicolumn{2}{|c|}{ No interactions } & \multicolumn{2}{|c|}{ Interactions } & \multicolumn{2}{|c|}{ No interactions } & \multicolumn{2}{|c|}{ Interactions } \\
\hline & 1.86 & {$[0.20]^{* * *}$} & 3.54 & {$[1.37]^{* *}$} & 2.08 & {$[0.22] * * *$} & 3.97 & {$[1.36] * * *$} \\
\hline Number of available plans & 0.41 & {$[0.28]$} & 0.52 & {$[0.29]^{*}$} & & & & \\
\hline $\begin{array}{l}\text { Above-minimum spending if stay }(\$ 100 \mathrm{~s}) \\
\times \text { number of available plans }\end{array}$ & & & -0.03 & {$[0.03]$} & & & & \\
\hline \multicolumn{9}{|l|}{ Number of available plans within } \\
\hline$\$ 100$ of minimum & & & & & 0.55 & {$[0.26]^{* *}$} & 0.88 & {$[0.29]^{* * *}$} \\
\hline$\$ 100-200$ of minimum & & & & & 0.56 & {$[0.29] *$} & 0.61 & {$[0.29] * *$} \\
\hline$\$ 200-300$ of minimum & & & & & 0.46 & {$[0.27] *$} & 0.40 & {$[0.28]$} \\
\hline$\$ 300-400$ of minimum & & & & & 0.42 & {$[0.25]^{*}$} & 0.33 & {$[0.27]$} \\
\hline$\$ 400-500$ of minimum & & & & & 0.49 & {$[0.26]^{*}$} & 0.45 & {$[0.29]$} \\
\hline$>\$ 500$ of minimum & & & & & 0.32 & {$[0.26]$} & 0.58 & {$[0.28] * *$} \\
\hline \multicolumn{9}{|c|}{ Above-minimum spending if stay $(\$ 100 s) \times$ number of available plans within } \\
\hline$\$ 100$ of minimum & & & & & & & -0.08 & {$[0.03] * *$} \\
\hline$\$ 100-200$ of minimum & & & & & & & 0.01 & {$[0.03]$} \\
\hline$\$ 200-300$ of minimum & & & & & & & 0.04 & {$[0.03]$} \\
\hline$\$ 300-400$ of minimum & & & & & & & 0.02 & {$[0.03]$} \\
\hline$\$ 400-500$ of minimum & & & & & & & -0.01 & {$[0.03]$} \\
\hline$>\$ 500$ of minimum & & & & & & & -0.06 & {$[0.03]^{* *}$} \\
\hline 2008 & 1.18 & [1.48] & 1.12 & {$[1.50]$} & 1.76 & [1.49] & 1.30 & {$[1.58]$} \\
\hline 2009 & 1.66 & {$[2.05]$} & 1.63 & {$[2.06]$} & 2.30 & {$[2.00]$} & 1.67 & {$[2.11]$} \\
\hline 2010 & 2.91 & [3.09] & 2.87 & [3.12] & 3.71 & [2.94] & 3.23 & [3.08] \\
\hline
\end{tabular}

Notes: Observations: 3,645,570. Standard errors from cluster-robust variance estimator clustered at the region-year level are in brackets. All models include year fixed effects, individual fixed effects and controls for time-varying health. The number of plans by cost category and above-minimum spending in the status quo plan are defined using the ex post approach and assuming perfectly inelastic demand for drugs.

$* * *$ Significant at the 1 percent level.

** Significant at the 5 percent level.

* Significant at the 10 percent level.

costs of their status quo plan in the upcoming year. Here we implement and report results from five alternative modeling approaches. First, we rely on the same ex post approach used above, but now we assume perfectly inelastic demand for prescription drugs. That is, we hold the drug consumption constant across all plans despite potentially large differences across plans in the OOP prices of drugs.

The results from these models are in Table 11. These results replicate all of the insights from the elastic models above. The most important difference is that in this version, the moderately large positive main effect on the number of plans achieves statistical significance at the 10 percent level in the second model. As before, the interaction term remains insignificant and small. This is the opposite of a choice overload effect. Consistent with the ex post elastic results above, adding lower cost plans to the choice set increases switching. As before, the magnitude of this effect falls as the OOP costs of the additional plans grow and the effect of adding the most expensive plans is indistinguishable from zero.

Next, we implement an ex ante approach that assumes people choose based on the drug consumption in the current year (rather than the next year) but on plan design in the next year, just as in the ex post approach. In this approach, the cost calculator combines the individual's claims from the current year with the plans' formulary coverage and premiums from the upcoming year for which the person is making an enrollment decision. This approach mimics the costs that an individual would be shown by the online CMS "plan finder" tool if they followed the tool's prompt and 
Table 12-Parameter Estimates from Ex Ante Models of Switching, 2007-2010

\begin{tabular}{|c|c|c|c|c|c|c|c|c|}
\hline \multirow[b]{3}{*}{$\begin{array}{l}\text { Above-minimum spending if stay } \\
\text { in status quo plan }(\$ 100 \mathrm{~s})\end{array}$} & \multicolumn{4}{|c|}{$\begin{array}{l}\text { Elasticity of demand } \\
\text { for drugs }=-0.54\end{array}$} & \multicolumn{4}{|c|}{$\begin{array}{l}\text { Perfectly inelastic demand } \\
\text { for drugs }\end{array}$} \\
\hline & \multicolumn{2}{|c|}{$\begin{array}{c}\text { Number of plans } \\
\text { overall }\end{array}$} & \multicolumn{2}{|c|}{$\begin{array}{c}\text { Number of plans } \\
\text { by cost }\end{array}$} & \multicolumn{2}{|c|}{$\begin{array}{c}\text { Number of plans } \\
\text { overall }\end{array}$} & \multicolumn{2}{|c|}{$\begin{array}{c}\text { Number of plans } \\
\text { by cost }\end{array}$} \\
\hline & 1.78 & {$[0.35] * * *$} & 2.34 & {$[0.52] * * *$} & 1.12 & {$[0.16] * * *$} & 1.26 & {$[0.19] * * *$} \\
\hline Number of available plans & 0.41 & {$[0.29]$} & & & 0.42 & {$[0.28]$} & & \\
\hline \multicolumn{9}{|l|}{ Number of available plans within } \\
\hline$\$ 100$ of minimum & & & 0.50 & {$[0.26]^{*}$} & & & 0.50 & {$[0.26]^{*}$} \\
\hline$\$ 100-200$ of minimum & & & 0.55 & {$[0.28] *$} & & & 0.55 & {$[0.29] *$} \\
\hline$\$ 200-300$ of minimum & & & 0.48 & {$[0.26] *$} & & & 0.45 & {$[0.27] *$} \\
\hline$\$ 300-400$ of minimum & & & 0.41 & {$[0.25]^{*}$} & & & 0.41 & {$[0.25]$} \\
\hline$\$ 400-500$ of minimum & & & 0.47 & {$[0.27] *$} & & & 0.47 & {$[0.27] *$} \\
\hline$>\$ 500$ of minimum & & & 0.18 & {$[0.26]$} & & & 0.37 & {$[0.27]$} \\
\hline 2008 & 0.18 & {$[1.41]$} & 1.12 & {$[1.41]$} & 0.74 & {$[1.40]$} & 1.06 & {$[1.40]$} \\
\hline 2009 & 0.58 & {$[2.05]$} & 1.87 & {$[1.93]$} & 1.66 & {$[1.95]$} & 1.95 & {$[1.90]$} \\
\hline 2010 & 1.86 & {$[3.13]$} & 3.30 & {$[2.85]$} & 2.85 & {$[2.95]$} & 3.34 & {$[2.84]$} \\
\hline
\end{tabular}

Notes: Observations: 3,644,298. Standard errors from cluster-robust variance estimator clustered at the region-year level are in brackets. All models include year fixed effects, individual fixed effects, and controls for time-varying health. The above-minimum spending in the status quo plan is defined using the ex ante approach.

*** Significant at the 1 percent level.

** Significant at the 5 percent level.

* Significant at the 10 percent level.

entered current drug consumption. ${ }^{35}$ Thus the second alternative approach we report is this ex ante approach assuming elastic demand for drugs, while the third alternative is the ex ante version assuming perfectly inelastic demand for drugs.

The results from the ex ante models of switching are reported in Table 12. To streamline the presentation, we report both the elastic and inelastic versions but from only equation (1). ${ }^{36}$ Increasing the relative cost of remaining in the status quo plan promotes switching, as does expanding the availability of all but the most expensive plans. As with the ex post inelastic results shown in Table 11, the unreported results from both the elastic and inelastic versions of the ex ante version of equation (2) show that the total number of plans has positive, moderately large effect on switching and is statistically significant at $p<0.10$.

For the final alternative approach, in place of the ex post approach's use of the person's actual prescription drug use in the upcoming year we instead employ a "rational expectations" assumption. ${ }^{37}$ This approach, developed in the context of Part D in Abaluck and Gruber (2011), is based on the idea that individuals may be uncertain about their individual future drug consumption but instead may have expectations regarding the possible distribution of expenses that they may have next year based on their current health and drug consumption patterns. In the rational expectations modeling approach, the analyst attempts to approximate those expectations by assuming that the observed ex post outcomes of similar people calculated for

\footnotetext{
${ }^{35} \mathrm{We}$ are thankful to a referee for pointing out the importance of considering this approach especially given the design of the plan finder tool.

${ }^{36}$ The results from these alternative results from models estimated by equation (2) are available from the authors.

${ }^{37} \mathrm{We}$ are thankful to a referee for suggesting we implement this alternative approach.
} 
Table 13-Parameter Estimates from "Rational Expectations" Models of Switching, 2007-2010

\begin{tabular}{|c|c|c|c|c|c|c|c|c|}
\hline \multirow[b]{3}{*}{$\begin{array}{l}\text { Above-minimum spending if } \\
\text { stay in status quo plan }(\$ 100 \mathrm{~s})\end{array}$} & \multicolumn{4}{|c|}{$\begin{array}{l}\text { Elasticity of demand } \\
\text { for drugs }=-0.54\end{array}$} & \multicolumn{4}{|c|}{$\begin{array}{l}\text { Perfectly inelastic demand } \\
\text { for drugs }\end{array}$} \\
\hline & \multicolumn{2}{|c|}{$\begin{array}{c}\text { Number of plans } \\
\text { overall }\end{array}$} & \multicolumn{2}{|c|}{$\begin{array}{c}\text { Number of plans } \\
\text { by cost }\end{array}$} & \multicolumn{2}{|c|}{$\begin{array}{c}\text { Number of plans } \\
\text { overall }\end{array}$} & \multicolumn{2}{|c|}{$\begin{array}{c}\text { Number of plans } \\
\text { by cost }\end{array}$} \\
\hline & 5.48 & {$[0.54]^{* * *}$} & 6.40 & {$[0.67]^{* * *}$} & 2.57 & {$[0.39]^{* * *}$} & 2.76 & {$[0.44] * * *$} \\
\hline Number of available plans & 0.32 & {$[0.40]$} & & & 0.44 & {$[0.28]$} & & \\
\hline \multicolumn{9}{|l|}{ Number of available plans within } \\
\hline$\$ 100$ of minimum & & & 0.54 & {$[0.28]^{*}$} & & & 0.46 & {$[0.29]$} \\
\hline$\$ 100-200$ of minimum & & & 0.55 & {$[0.28]^{*}$} & & & 0.57 & {$[0.29] *$} \\
\hline$\$ 200-300$ of minimum & & & 0.43 & {$[0.27]$} & & & 0.47 & {$[0.25]^{*}$} \\
\hline$\$ 300-400$ of minimum & & & 0.31 & {$[0.26]$} & & & 0.38 & {$[0.25]$} \\
\hline$\$ 400-500$ of minimum & & & 0.27 & {$[0.27]$} & & & 0.46 & {$[0.25]^{*}$} \\
\hline$>\$ 500$ of minimum & & & -0.18 & {$[0.28]$} & & & 0.38 & {$[0.26]$} \\
\hline 2008 & -2.32 & {$[1.67]$} & 0.28 & {$[1.67]$} & -0.74 & {$[1.49]$} & 0.40 & {$[1.55]$} \\
\hline 2009 & -3.86 & {$[2.78]$} & -0.5 & {$[2.27]$} & 1.38 & {$[2.12]$} & 1.66 & {$[2.01]$} \\
\hline 2010 & -1.76 & {$[4.45]$} & 1.24 & {$[3.28]$} & 2.90 & {$[3.22]$} & 3.52 & {$[2.99]$} \\
\hline
\end{tabular}

Notes: Observations: 3,483,504. Standard errors from cluster-robust variance estimator clustered at the region-year level are in brackets. All models include year fixed effects, individual fixed effects and controls for time-varying health. The number of plans by cost category and above-minimum spending in the status quo plan are defined using the "rational expectations" approach.

*** Significant at the 1 percent level.

** Significant at the 5 percent level.

* Significant at the 10 percent level.

each available option represent the individual's perceived distribution of expenses. Here we adopt the Abaluck and Gruber (2011) methodology wholesale and define "similar" based on the deciles of their prior year's gross drug spending, days' supply of branded drugs, and days' supply of generic drugs. For our purposes, for each plan we then calculate the average of the ex post calculated OOP costs among all of the similar individuals in the region. Our one point of divergence from the preceding method is that we average across only non-subsidy PDP enrollees in the same region, i.e., all of those for whom we had calculated costs in the plan under the ex post approach. ${ }^{38}$

Table 13 provides the results from the models that rely on the rational expectations approach to estimating the individuals' future costs of their status quo plan. Of all the modeling approaches, this one yields the largest main effects of the status quo plan's costs on switching. For example, the first model reported in this table implies that each $\$ 100$ increase in the status quo plan's relative costs leads to a 5.5 percentage point increase in the probability of switching. As before, expanding the choice set by adding more lower cost options increases the probability of switching whereas adding high cost options has no effect.

\footnotetext{
${ }^{38}$ This contrasts with the Abaluck and Gruber (2011) approach, as they used a random sample of 200 people from the population of all similar individuals in their data calculated through every plan to define the type-specific calculated averages for the plan. For example, they would have used a Medicare Advantage enrollee in Alaska in their calculation of the rational expectations measure for the type-specific expected OOP costs in a stand-alone PDP in Florida, but they would not have used another similar Florida PDP enrollee if she was not among the 200 randomly chosen individuals.
} 


\section{Conclusions}

Our analysis yields two primary conclusions regarding the influence of choice overload and experience on inertia in the context of switching between Medicare PDPs. First, within the range of choice set sizes in Part D through 2010, increasing the number of available low cost options (within $\$ 500$ of the individual's minimum cost plan) increases individuals' likelihoods of switching plans. By switching, individuals reduce their own annual spending by an average of over $\$ 200$. Our results for indiscriminate expansions of the choice set typically show no effect on switching rates, albeit several versions of our models yield marginally significant increases in switching due to larger choice sets. Likewise, increases in the number of plans does not diminish people's responsiveness to their status quo plans' costs.

These results represent consilience among several related domains of research in which adding options promotes switching (e.g., Lancaster 1966, Huber, Payne, and Puto 1982, and Simonson 1989). These results contradict the subset of existing research on choice overload that is commonly appropriated for the Part D context. Although differences in the existence of choice overload can be found across prior studies, a widely acknowledged precondition for choice overload to exist is that consumers must not have strong existing preferences for certain products or product attributes (Iyengar and Lepper 2000). Our results suggest that such preconditions are not met in Part D. Further, the increase in switching from adding low cost plans and the irrelevance of adding high cost plans is inconsistent with choice overload. These results are consistent with models in which consumers ignore options that are strongly dominated on an attribute such as costs.

One common hypothesis regarding choice overload is that its effects are nonlinear. Nonlinearity implies that marginal changes in size in the relatively large choice sets that have existed in Part D may have no effect on inertia whereas marginal changes in small choice sets that have not yet existed in Part D may have either positive or negative effects. This hypothesis is not supported by our consistent finding that adding plans to the choice sets that existed in Part D for 2007-2010 increased switching as long as those plans are not too expensive. Although it is possible that the magnitude and even sign of the effects of adding options may vary across choice set sizes, researchers cannot directly test how switching decisions may be affected by changes in choice set size if the choice sets were extremely restricted relative to those under Part D currently. Any predictions about such effects are vastly out of sample.

Research from other contexts, however, provides some potential insights. The experimental research overall has not found any evidence of non-linearities in the choice overload effect (Scheibehenne, Greifeneder, and Todd 2010), and other empirical research found evidence of choice overload due to expansions in choice set size at sizes even larger than those we study (Kempf and Ruenzi 2006). The experiments of Besedeš et al. (2012) found that the marginal benefits of larger choice sets actually increased with choice set size. On balance then, large but previously unimplemented restrictions of Part D choice sets may have positive or negative consequences not evident from the marginal changes studied here. Given that switching increases with additional low cost options, however, the data do not support the view that at even the smallest choice set sizes in Part D to date consumers 
are simply too overwhelmed to pay attention to their status quo plans' costs relative to the alternatives.

Our second primary conclusion is that individuals did not become less sensitive to their status quo plans' costs over time. In fact, Part D enrollees' switching decisions for 2007, the first year possible for switching, were less responsive to high costs of their status quo plan than any other year from 2008 through 2010. Likewise, above-minimum spending in 2010 remained below their 2007 levels, and switching rates were virtually flat throughout the study period. These patterns hold even among the cohort that enrolled in a PDP on January 1, 2006 and remained in the market without a low-income subsidy through the end of 2010. Among this most experienced cohort, the 2010 switching rates were higher and above-minimum spending in percentage terms lower than any prior year.

These within-person changes over time in Part D relate to several of the well-known articles on inertia from other contexts. For example, our finding that inertia does not increase over time is consistent with the results in Madrian and Shea (2001) showing that participation in the firm's retirement plan increased with the employee's tenure with the firm. In contrast with Part D, however, in their context of retirement planning neither improvements in the available information nor individual-specific learning are likely to be important as consumers have little ability to discern whether their prior choices maximized their objective functions. Similarly, another frequently cited article demonstrating consumers' inattentiveness relied on choices of only entirely inexperienced first-time consumers, precluding its ability to consider how such attention evolves over time (DellaVigna and Malmendier 2006).

Regarding the within-person changes over time observed here, the identification comes from a relatively short time window that incorporates two to four switching decisions per person. Thus it remains to be determined how these effects have evolved since 2010. For example, the within-person time trends observed here may not be generalizable due to the recession that occurred during this time period or due to any one-time improvements in the complementary information market, e.g., from improvements in the CMS plan finder website. The overall similarity between 2007 and 2010 in consumers' responsiveness to their status quo plans' costs suggests that the within-person time trends observed here, coupled with the observed negative effect of individual-specific experience, may have resulted from the newness of Part D in ways that may not continue as Part D matures.

Throughout the early years of Part D, concerns have been raised that competition was suboptimal because of consumer inertia (e.g., Heiss, McFadden, and Winter 2010). This view is based on the presumptions that inertia in Part D is both widespread and anticompetitive. Our results here build on prior research and call into question both presumptions. To the extent that inertia is present, Dube, Hitsch, and Rossi 2009 point out that it should increase competition for initial enrollment choices. Our data show that by 2010, fully half of those who had ever previously enrolled in a PDP were no longer in their original plans. This observed level of turnover for Part D, in conjunction with CMS regulations that prohibit insurers from offering teaser rates to new enrollees, limits firms' ability to harvest gains from existing enrollees without also losing potential new enrollees. Finally, in contrast with individuals' likelihood of remaining in their status quo plan growing over time, our results show that over time people became more likely to switch away from their 
status quo in response to it becoming relatively much more expensive. Collectively the evidence here provides little support for fears that consumer inertia is heightened by either greater time or larger choice sets in Part D.

\section{REFERENCES}

AARP. 2007. "Prescription Drugs and Medicare Part D: A Report on Access, Satisfaction, and Cost." November, Washington, DC. http://assets.aarp.org/rgcenter/health/rx_medicared.pdf (accessed May 10, 2013).

Abaluck, Jason T., and Jonathan Gruber. 2009. "Choice Inconsistencies Among the Elderly: Evidence from Plan Choice in the Medicare Part D Program.” National Bureau of Economic Research Working Paper 14759.

Abaluck, Jason T., and Jonathan Gruber. 2011. "Choice Inconsistencies among the Elderly: Evidence from Plan Choice in the Medicare Part D Program.” American Economic Review 101 (4): 1180-210.

Abrevaya, Jason. 1997. "The Equivalence of Two Estimators of the Fixed-Effects Logit Model." Economics Letters 55 (1): 41-43.

Banzhaf, H. Spencer, and V. Kerry Smith. 2007. "Meta-Analysis in Model Implementation: Choice Sets and the Valuation of Air Quality Improvements." Journal of Applied Econometrics 22 (6): 1013-31.

Besedeš, Tibor, Cary Deck, Sudipta Sarangi, and Mikhael Shor. 2012. "Decision-Making Strategies and Performance among Seniors." Journal of Economic Behavior and Organization 81 (2): 524-33.

Bundorf, M. Kate, and Helena Szrek. 2010. "Choice Set Size and Decision Making: The Case of Medicare Part D Prescription Drug Plans." Medical Decision Making 30 (5): 582-93.

Cameron, A. Colin, Jonah B. Gelbach, and Douglas L. Miller. 2008. "Bootstrap-Based Improvements for Inference with Clustered Errors." Review of Economics and Statistics 90 (3): 414-27.

Centers for Medicare and Medicaid Services. 2007. "2008 Call Letter." http://www.medicareadvocacy. org/Projects/SNP\%20Conference/BackgroundInfo/CMS_04.19.07.2008CallLetter.pdf (accessed October 20, 2014).

Centers for Medicare and Medicaid Services. 2008. "Medicare Prescription Drug Benefit's Projected Costs Continue to Drop.” Press Release. http://www.cms.gov/Newsroom/MediaReleaseDatabase/ Press-Releases/2008-Press-Releases-Items/2008-01-31.html (accessed October 20, 2014).

Centers for Medicare and Medicaid Services. 2011. "Prescription Drug Plan Formulary, Pharmacy Network, and Pricing Information Files.” http://www.cms.gov/Research-Statistics-Data-and-Systems/ Files-for-Order/NonIdentifiableDataFiles/PrescriptionDrugPlanFormularyPharmacyNetworkandPr icingInformationFiles.html (accessed October 20, 2014).

Centers for Medicare and Medicaid Services. 2014a. "Chronic Conditions Data Warehouse." www. ccwdata.org/ (accessed October 20, 2014).

Centers for Medicare and Medicaid Services. 2014b. "Denominator File." https://www.cms.gov/ Research-Statistics-Data-and-Systems/Files-for-Order/IdentifiableDataFiles/DenominatorFile.html (accessed October 20, 2014).

Centers for Medicare and Medicaid Services. 2014c. "Master Beneficiary Summary File." https:// www.ccwdata.org/web/guest/medicare-data (accessed October 20, 2014).

Centers for Medicare and Medicaid Services. 2014d. "Part D Claims Data." http://www.cms. gov/Medicare/Prescription-Drug-Coverage/PrescriptionDrugCovGenIn/PartDData.html (accessed October 20, 2014).

Chernev, Alexander, Ulf Böckenholt, and Joseph Goodman. 2010. "Commentary on Scheibehenne, Greifeneder, and Todd: Choice Overload: Is There Anything to It?" Journal of Consumer Research 37 (3): 426-28.

Cummings, Janet R., Thomas Rice, and Yaniv Hanoch. 2009. "Who Thinks That Part D Is Too Complicated? Survey Results on the Medicare Prescription Drug Benefit." Medical Care Research and Review 66 (1): 97-115.

Day, Rosemarie, and Pamela Nadash. 2012. "New State Insurance Exchanges Should Follow the Example of Massachusetts by Simplifying Choices Among Health Plans." Health Affairs 31 (5): 982-89.

DellaVigna, Stefano, and Ulrike Malmendier. 2006. "Paying Not to Go to the Gym." American Economic Review 96 (3): 694-719.

Diehl, Kristin, and Cait Poynor. 2010. "Great Expectations?! Assortment Size, Expectations, and Satisfaction." Journal of Marketing Research 47 (2): 312-22. 
Dube, Jean-Pierre, Gunter J. Hitsch, and Peter E. Rossi. 2009. "Do Switching Costs Make Markets Less Competitive?" Journal of Marketing Research 46 (4): 435-45.

Dube, Jean-Pierre, Gunter J. Hitsch, and Peter E. Rossi. 2010. "State Dependence and Alternative Explanations for Consumer Inertia." RAND Journal of Economics 41 (3): 417-45.

Eicheldinger, Celia, and Arthur Bonito. 2008. "More Accurate Racial and Ethnic Codes for Medicare Administrative Data." Health Care Financing Review 29 (3): 27-42.

Greene, William H. 2004. "The Behaviour of the Maximum Likelihood Estimator of Limited Dependent Variable Models in the Presence of Fixed Effects." Econometrics Journal 7 (1): 98-119.

Hauser, John R., and Birger Wernerfelt. 1990. "An Evaluation Cost Model of Consideration Sets." Journal of Consumer Research 16 (4): 393-408.

Heckman, James J. 1981. "The Incidental Parameters Problem and the Problem of Initial Conditions in Estimating a Discrete Time-Discrete Data Stochastic Process.” In Structural Analysis of Discrete Data with Applications, edited by Charles F. Manski and Daniel McFadden, 179-96. Cambridge, MA: MIT Press.

Heilman, Carrie M., Douglas Bowman, and Gordon P. Wright. 2000. "The Evolution of Brand Preferences and Choice Behaviors of Consumers New to a Market." Journal of Marketing Research 37 (2): 139-55.

Heiss, Florian, Daniel McFadden, and Joachim Winter. 2006. "Who Failed to Enroll in Medicare Part D, And Why? Early Results.” Health Affairs 25 (5): w344-54.

Heiss, Florian, Daniel McFadden, and Joachim Winter. 2010. "Mind the Gap! Consumer Perceptions and Choices of Medicare Part D Prescription Drug Plans." In Research Findings in The Economics of Aging, edited by David A. Wise, 413-484. Chicago: University of Chicago Press.

Hoadley, Jack. 2008. "Medicare Part D: Simplifying the Program and Improving the Value of Information for Beneficiaries." The Commonwealth Fund Issue Brief 39: 1-15.

Huber, Joel, John W. Payne, and Christopher Puto. 1982. "Adding Asymmetrically Dominated Alternatives: Violations of Regularity and the Similarity Hypothesis." Journal of Consumer Research 9 (1): 90-98.

Huskamp, Haiden A., Meredith B. Rosenthal, Richard G. Frank, and Joseph P. Newhouse. 2000. "The Medicare Prescription Drug Benefit: How Will The Game Be Played?" Health Affairs 19 (2): 8-23.

Israel, Mark. 2005a. "Services as Experience Goods: An Empirical Examination of Consumer Learning in Automobile Insurance." American Economic Review 95 (5): 1444-63.

Israel, Mark. 2005b. "Tenure Dependence in Consumer-Firm Relationships: An Empirical Analysis of Consumer Departures from Automobile Insurance Firms.” RAND Journal of Economics 36 (1): 165-92.

Iyengar, Sheena S., Gur Huberman, and Wei Jiang. 2004. "How Much Choice is Too Much? Contributions to 401(k) Retirement Plans." In Pension Design and Structure: New Lessons from Behavioral Finance, edited by Olivia S. Mitchell and Stephen P. Utkus, 83-96. Oxford: Oxford University Press.

Iyengar, Sheena S., and Mark R. Lepper. 2000. "When Choice is Demotivating: Can We Desire Too Much of a Good Thing?” Journal of Personality and Social Psychology 79 (6): 995-1006.

Katz, Ethan. 2001. "Bias in Conditional and Unconditional Fixed Effects Logit Estimation." Political Analysis 9 (4): 379-84.

Kempf, Alexander, and Stefan Ruenzi. 2006. "Status Quo Bias and the Number of Alternatives: An Empirical Illustration from the Mutual Fund Industry." Journal of Behavioral Finance 7 (4): 204-13.

Ketcham, Jonathan D., Claudio Lucarelli, Eugenio J. Miravete, and M. Christopher Roebuck. 2012. "Sinking, Swimming, or Learning to Swim in Medicare Part D." American Economic Review 102 (6): 2639-73.

Ketcham, Jonathan D., Claudio Lucarelli, and Christopher A. Powers. 2015. "Paying Attention or Paying Too Much in Medicare Part D: Dataset.” American Economic Review. http://dx.doi.org/10.1257/ aer.20120651.

Klemperer, Paul. 1995. "Competition When Consumers Have Switching Costs: An Overview with Applications to Industrial Organization, Macroeconomics, and International Trade." Review of Economic Studies 62 (4): 515-39.

Kuminoff, Nicolai V., V. Kerry Smith, and Christopher Timmins. 2013. "The New Economics of Equilibrium Sorting and Policy Evaluation Using Housing Markets.” Journal of Economic Literature 51 (4): 1007-62.

Lancaster, K. J. 1966. "A New Approach to Consumer Theory." Journal of Political Economy 74: 132-57.

List, John A. 2003. “Does Market Experience Eliminate Market Anomalies?” Quarterly Journal of Economics 118 (1): 41-71. 
List, John A. 2004. "Neoclassical Theory versus Prospect Theory: Evidence from the Marketplace." Econometrica 72 (2): 615-25.

List, John A. 2006. "The Behavioralist Meets the Market: Measuring Social Preferences and Reputation Effects in Actual Transactions." Journal of Political Economy 114 (1): 1-37.

List, John A., and Daniel L. Millimet. 2008. "The Market: Catalyst for Rationality and Filter of Irrationality." B E Journal of Economic Analysis and Policy: Frontiers of Economic Analysis and Policy $8(1): 1-55$.

Madrian, Brigitte C., and Dennis F. Shea. 2001. "The Power of Suggestion: Inertia in 401(k) Participation and Savings Behavior." Quarterly Journal of Economics 116 (4): 1149-87.

Medicare Today. 2012. "Seniors' Opinions About Medicare Rx: 7th Year Update." http://heartland.org/ policy-documents/seniors-opinions-about-medicare-rx-7th-year-update (accessed May 8, 2013).

Mehta, Nitin, Surendra Rajiv, and Kannan Srinivasan. 2003. "Price Uncertainty and Consumer Search: A Structural Model of Consideration Set Formation." Marketing Science 22 (1): 58-84.

Mikels, Joseph A., Andrew E. Reed, and Kosali I. Simon. 2009. "Older Adults State Lower Willingness to Pay for Choice Than Young Adults." Journal of Gerontology: Psychological Sciences 64B (4): 443-46.

Miravete, Eugenio J. 2003. "Choosing the Wrong Calling Plan? Ignorance and Learning." American Economic Review 93 (1): 297-310.

Nerlove, Marc. 1967. "Experimental Evidence on the Estimation of Dynamic Economic Relations from a Time Series of Cross-Sections." Economic Studies Quarterly 18 (3): 42-74.

Nerlove, Marc. 1971. "Further Evidence on the Estimation of Dynamic Economic Relations from a Time Series of Cross-Sections." Econometrica 39 (2): 359-82.

Neuman, Patricia, and Juliette Cubanski. 2009. "Medicare Part D Update - Lessons Learned and Unfinished Business." New England Journal of Medicine 361: 406-14.

Neyman, Jerzy, and Elizabeth L. Scott. 1948. "Consistent Estimates Based on Partially Consistent Observations." Econometrica 16 (1): 1-32.

Osborne, Matthew. 2011. "Consumer Learning, Switching Costs, and Heterogeneity: A Structural Examination." Quantitative Marketing and Economics 9: 25-70.

Prince, Jeffrey T. 2011. "Relating Inertia and Experience in Technology Markets: An Analysis of Households' Personal Computer Choices.” Applied Economics 43 (28-30): 4501-14.

Querfurth, Henry W., and Frank M. LaFerla. 2010. "Mechanisms of Disease: Alzheimer's Disease." New England Journal of Medicine 362 (4): 329-44.

Rhode Island Healthcare Reform Commission. 2011. "Issue Brief: Should the Exchange Offer Manageable and Meaningful Choices of Health Plans." http://www.statecoverage.org/files/RI_issue_ brief_no._2_-_standardizing_health_plans.pdf (accessed May 8, 2013).

Samuelson, William, and Richard Zeckhauser. 1988. "Status Quo Bias in Decision Making." Journal of Risk and Uncertainty 1 (1): 7-59.

Scheibehenne, Benjamin. 2008. "The Effect of Having Too Much Choice." PhD diss. Humboldt University.

Scheibehenne, Benjamin, Raner Greifeneder, and Peter M. Todd. 2010. "Can There Ever Be Too Many Options? A Meta-Analytic Review of Choice Overload." Journal of Consumer Research 37: 409-25.

Scheibehenne, Benjamin, Raner Greifeneder, and Peter M. Todd. 2011. "Reply to Chernev, Böckenholt and Goodman (2010), Choice Overload: Is there Anything To It?" http://scheibehenne.com/Rep lyToChernevBoeckenholdtGoodman2010.pdf (accessed October 20, 2014).

Schwartz, Barry. 2004. The Paradox of Choice: Why More is Less. New York: Harper Collins Publishers Inc.

Shea, Dennis G., Joseph V. Terza, Bruce C. Stuart, and Becky Briesacher. 2007. "Estimating the Effects of Prescription Drug Coverage for Medicare Beneficiaries." Health Services Research 43 (3 Pt. 1): 933-49.

Simonson, Itamar. 1989. "Choice Based on Reasons: The Case of Attraction and Compromise Effects." Journal of Consumer Research 16 (2): 158-74

Speigler, Ran. 2011. Bounded Rationality and Industrial Organization. New York: Oxford University Press.

Stigler, George J. 1961. "The Economics of Information.” Journal of Political Economy 69: 213-25.

Stigler, George J., and Gary S. Becker. 1977. "De Gustibus Non Est Disputandum." American Economic Review 67 (2): 76-90.

Tanius, Betty E., Stacey Wood, Yaniv Hanoch, and Thomas Rice. 2009. "Aging and Choice: Applications to Medicare Part D." Judgment and Decision Making 4 (1): 92-101.

Tversky, Amos, and Eldar Shafir. 1992. "Choice Under Conflict: The Dynamics of Deferred Decision." Psychological Science 3 (6): 358-61. 
Copyright of American Economic Review is the property of American Economic Association and its content may not be copied or emailed to multiple sites or posted to a listserv without the copyright holder's express written permission. However, users may print, download, or email articles for individual use. 